8-2014

\title{
Retail Store Density and the Cost of Greenhouse Gas Emissions
}

Gerard. P. Cachon

University of Pennsylvania

Follow this and additional works at: https://repository.upenn.edu/fnce_papers

Part of the Finance and Financial Management Commons

\section{Recommended Citation}

Cachon, G. P. (2014). Retail Store Density and the Cost of Greenhouse Gas Emissions. Management Science, 60 (8), 1907-1925. http://dx.doi.org/10.1287/mnsc.2013.1819 


\title{
Retail Store Density and the Cost of Greenhouse Gas Emissions
}

\begin{abstract}
The density, size, and location of stores in a retailer's network influences both the retailer's and the consumers' costs. With stores few and far between, consumers must travel a long distance to shop, whereas shopping trips are shorter with a dense network of stores. The layout of the retail supply chain is of interest to retailers who have emission reduction targets and urban planners concerned with sprawl. Are small local shops preferred over large, "big-box" retailers? A model of the retail supply chain is presented that includes operating costs (such as fuel and rent for floor space) as well as a cost for environmental externalities associated with carbon emissions. A focus on exclusively minimizing operating costs may substantially increase emissions (by $67 \%$ in one scenario) relative to the minimum level of emissions. A price on carbon is an ineffective mechanism for reducing emissions. The most attractive option is to improve consumer fuel efficiency-doubling the fuel efficiency of cars reduces longrun emissions by about one-third, whereas an improvement in truck fuel efficiency has a marginal impact on total emissions.
\end{abstract}

\section{Keywords}

sustainability, k-median, traveling salesman problem, carbon tax, cap-and-trade

Disciplines

Business | Finance and Financial Management 


\title{
Retail Store Density and the Cost of Greenhouse Gas Emissions*
}

\author{
Gérard P. Cachon \\ The Wharton School · University of Pennsylvania \\ cachon@wharton.upenn.edu ·opim.wharton.upenn.edu/ cachon
}

August 25, 2011; revised July 18, 2012; March 18, 2013; July 9, 2013

\begin{abstract}
The density, size and location of stores in a retailer's network influences both the retailer's and the consumers' costs - with stores few and far between, consumers must travel a long distance to shop, whereas shopping trips are shorter with a dense network of stores. The layout of the retail supply chain is of interest to retailers who have emission reduction targets and urban planners concerned with sprawl - are small local shops preferred over large, "big-box", retailers? A model of the retail supply chain is presented that includes operating costs (such as fuel and rent for floor space) as well as a cost for environmental externalities associated with carbon emissions. It is found that that a focus on minimizing exclusively operating costs may substantially increase emissions (by $67 \%$ in one scenario) relative to the minimum level of emissions. A price on carbon is an ineffective mechanism for reducing emissions. The most attractive option is to improve consumer fuel efficiency - doubling fuel efficiency of cars reduces long run emissions by about one third - while an improvement in truck fuel efficiency has a marginal impact on total emissions.

Keywords: Sustainability, k-median, traveling salesman problem, carbon tax, cap-and-trade

\footnotetext{
following: University of Maryland, Kellogg Operations Management Workshop, Stanford University, Harvard University, New York University, NSF Sponsored Symposium on Low University, and the University of Southern California. Thanks is also extended to the following for their helpful discussions: Dan Adelman, Saif Benjaafar, John Birge, John Jae Park, Erica Plambeck, Lawrence Robinson, Sergei Savin, Michael Toffel, Beril Toktay, Nico Savva, Sridhar Seshadri, Senthil Veeraraghavan, Sean Willems, and John Zhang. Previous versions of this paper were titled "Supply Chain Design and the Cost of Greenhouse
}

*For helpful feedback and comments, the author thanks seminar participants from the Carbon Supply Chains, University of Chicago, University of Michigan, Massachusetts Institute of Technology, University of Delaware, Georgia Institute of Technology, Columbia Gunnar Carlsson, Felipe Caro, Mark Daskin, Don Eisenstein, Michael Magazine, SeungGas Emissions"
\end{abstract}




\section{Introduction}

The combustion of fossil fuels is believed to contribute to climate change by adding carbon dioxide and other greenhouse gases to the atmosphere (IPCC 2007). Electric power generation and transportation are two major sources of these emissions - electric power accounts for 39\%, and transportation accounts for 31\% of $\mathrm{CO}_{2}$ emissions in the U.S. in 2009 (EPA 2011). Among transportation induced emissions, about $65 \%$ is due to the consumption of gasoline by personal vehicle use (EPA 2011).

Factors that influence the emissions generated by a supply chain network include the size of its facilities, the fuel efficiency of the vehicles used, the weight of the loads they carry, and the distance they travel. This paper focuses on the downstream supply chain - the portion that includes inbound replenishments to retail stores, the stores themselves and the "final mile" segment between the retail stores and consumers' homes. As the number of stores increases, thereby creating a dense network, stores shrink in size and consumers find themselves closer to some store, so they need not travel far to make their purchases. However, with more stores, the retailer must travel farther to replenish its stores and its total floor space grows as inventory productivity falls.

The density of retail stores is of interest to urban planners. One concern, among others, is that large retail stores contribute to a car culture that encourages consumers to drive further than what they would drive if smaller store formats were available closer to where they live (Owen 2009; Duany and Speck, 2010; Glaeser 2011; Shoup 2011). As an increase in vehicle miles traveled by consumers leads to additional emissions, environmentalists have been critical of "big-box" stores. The issue of retail store density is also relevant for a retailer's strategic planning. For one, a retailer's store density influences its desirability to consumers - all else equal, a consumer favors the convenience of a nearby store over a more distant store. For example, Pancras, Sriram and Kumar (2012) estimate in the context of a fast food retailer that consumers behave as if each mile of travel costs $\$ 0.60$. Second, the density decision is also important to retailers with emission reduction targets. For example, Walmart has pledged that it will remove 20 million metric tons of $\mathrm{CO}_{2}$ from its supply chain by 2015. These reductions can occur from the supply chain it directly controls (e.g., reductions in its fuel consumption), which are often called "scope 1" emissions. Alternatively, reductions can come from further down the supply chain (e.g., reductions in its consumer's fuel consumption), which are part of what is called "scope 3" emissions. While it is probably too costly to make major modifications to store density to achieve short term emission reduction targets, the size and location of stores can be substantially modified over a long run horizon of five or more years. For example, from 2006 to 2010, Walmart decreased the number of discount stores in the 
U.S. by a third (1209 to 803), increased the number of its larger supercenters by $60 \%$ (1713 to 2747) while also expanding its small store format, Neighborhood Markets, by nearly 60\% (100 to 158) (Source: 2010 10k filing.)

In this paper a model is developed in which a retailer chooses the size, location and number of stores to serve a region of customers. The retailer incurs costs for its physical space as well as costs that are proportional to the distance it travels to replenish its stores. Consumers also incur transportation costs that are proportional to the distance they must travel to shop at the nearest store to their home. While the retailer uses a truck for its replenishments and consumers use passenger vehicles (i.e., cars), both of their transportation costs are divided into three components: a variable operating cost (e.g., wear and tear on brakes and tires), a fuel consumption cost and an emissions cost (due to the consumption of fuel). Similarly, the retailer's space cost has three components: a variable operating cost (e.g., rent), an energy consumption cost (e.g., electricity and natural gas) and an emissions cost. Given a set of $n$ stores, a durable goods inventory model is developed to determine the amount of physical space the retailer needs. The retailer's transportation cost can be modeled by the well studied Traveling Salesman Problem (TSP). The consumer's transportation problem is equivalent to the continuous version of the well studied $k$ median problem. Thus, the retail store density problem combines an inventory model with the TSP and the $k$-median problem.

An optimal retail supply chain design is presented for three different objectives. The first ignores the cost of emissions and instead minimizes just the explicit operating costs incurred by the retailer and consumers, such as wear-and-tear on vehicles, fuel usage, rent and electricity consumption. This roughly represents that status quo in the United States in which there are no required taxes on carbon emissions. Alternatively, a supply chain design could be chosen to minimize total emissions. This objective avoids the debate as to the true cost of the externalities caused by emissions (e.g., Cline, 1992; Shelling 1992; Stern 2007; Arrow 2007; Weitzman 2007) by merely acting as if that cost is quite large. Comparing the supply chain that minimizes operating costs with the one that minimizes emissions allows for a measure of the consequence of choosing one objective over the other. For example, one can ask by how much emissions increase if operating costs are minimized, or by how much operating costs increase if emissions are minimized.

Between the two extremes of just minimizing operating costs or just minimizing emissions, a retail supply chain design is developed that minimizes total costs given an explicit price for carbon emissions. Naturally, if the price of carbon is assumed to be low, this objective leads to a supply chain that resembles the one that minimizes operating costs, whereas if the price of carbon is assumed to be high, it recommends a supply chain that is similar to the one that minimizes 
emissions. This model addresses the question of how high that price needs to be for the system to approximately minimize emissions.

There are several reasons to believe that failing to account for the cost of emissions leads to a poor retail supply chain design. The emission of carbon is an example of a negative production externality (Varian 1984) - the action of one reduces the utility of others. In this setting all agents emit carbon through their actions, and therefore they all contribute to this negative externality. It has been well established that self-interested agents tend to do "too much" of their action when there is a negative externality, i.e., they drive too much and use too much electricity and natural gas (Varian 1984). Of course, the importance of the distortion in actions from the socially optimal ones depends on the intensity of the externality.

In the context of the downstream supply chain, it is reasonable to conjecture that the negative effects of the carbon externality are substantial. For one, as already mentioned, it is possible that the true cost of emitting carbon is high due to its potential to have numerous negative consequences on our environment, such as climate change, ocean acidification, sea-level rise, and others. Next, it is already understood in the context of transportation that a retail truck is substantially more efficient at hauling goods than a passenger vehicle. A commonly used metric is the "cost per tonne-kilometer" - the cost to transport one tonne of goods the distance of one kilometer. In terms of this metric, a truck can be several orders of magnitude better than a car. Hence, in a product's journey from source to consumer home, it has been argued that costs and emissions can be reduced considerably by replacing one kilometer of car transport with a kilometer of truck transport (McKinnon and Woodburn, 1994). Given this reasoning, the downstream supply chain emissions are probably minimized if the retailer builds many small stores close to consumers. Finally, a retailer faces a tradeoff between store size and inventory productivity. Large stores that serve large market areas require less space per unit of product than small stores. Consequently, the energy intensity of small stores is higher. If retailers and consumers are not explicitly charged for the cost of carbon, it is plausible that a retailer will chose store locations and sizes that will lead to an undesirable level of emissions.

\section{The Retail Store Density Problem}

The retail store density problem focuses on the downstream supply chain. The retailer's task is to decide (i) the number, $n$, and location of its stores in a single (polygon) region of area $a$, (ii) the size of the stores, (iii) how to route replenishment deliveries to these stores, (iv) the quantity and timing of deliveries to the stores, and (v) the shape of the region. 
Consumers live uniformly throughout the region and they travel a straight line (i.e., the Euclidian norm, $L_{2}$ ) with their cars to shop at the nearest store from their home. The mean and standard deviation of demand per unit of time for the entire region are $\lambda$ and $\sigma$ respectively. Demand is independent across time and areas. Consumers incur a cost $c_{c}$ per unit of distance travelled per unit of product purchased. (The subscript " $c$ " refers to the consumers" "cars".) Let $d_{c}$ be the average round-trip distance a consumer travels to a store. Thus, the average travel cost per consumer per unit purchased is $c_{c} d_{c}$. All consumers purchase from the nearest store.

The retailer directly incurs two types of costs, one due to the transportation needed to replenish its stores and the other due to the operation of retail floor space. In terms of transportation, the retailer has a single warehouse where it receives goods from an outside supplier. The warehouse is collocated with one of the $n$ stores. The retailer has a single truck that is used to transport goods from the warehouse to the stores - all deliveries must start at the warehouse and end at the warehouse. Furthermore, the truck travels in straight lines between stores, delivers to all $n$ stores on each route, and completes its route instantly (i.e., fast enough such that transit time is not a major issue). The retailer incurs a cost of $c_{t}$ per unit of product delivered per unit of distance the truck travels. (As with $c_{c}$, the " $t$ " in $c_{t}$ refers to the type of vehicle used.) $c_{t}$ is a commonly used measure of transportation efficiency - it is analogous to "\$ per tonne-km". Let $d_{t}$ be the length of the truck's route, so the retailer's transportation cost per unit sold is $c_{t} d_{t}$.

Several components are included in the transportation costs $\left(\$ \mathrm{~kg}^{-1} \mathrm{~km}^{-1}\right)$ of vehicle type $j$, $j \in\{c, t\}:$

$$
c_{j}=\frac{v_{j}+f_{j}\left(p_{j}+e_{j} p_{e}\right)}{q_{j}},
$$

where $v_{j}$ is the non-fuel variable cost to transport the vehicle per unit of distance (e.g., $\left.\$ \mathrm{~km}^{-1}\right) ; f_{j}$ is the amount of fuel used to transport the vehicle per unit of distance (e.g., $l \mathrm{~km}^{-1}$ ); $p_{j}$ is the cost of fuel per unit of fuel (e.g., $\left.\$ l^{-1}\right)$; $e_{j}$ is the amount of emission released by the consumption of one unit of fuel (e.g., $\mathrm{kgCO} \mathrm{Cl}_{2} \mathrm{l}^{-1}$ ); $p_{e}$ is the cost of emissions per unit released (e.g., $\$ C \mathrm{O}_{2} \mathrm{~kg}^{-1}$ ); and $q_{j}$ is the load carried by the vehicle (e.g., $\mathrm{kg}$ ). The variable cost, $v_{j}$, includes depreciation on the vehicle, maintenance (such as tire replacement) and other costs that can be linked to the distance the vehicle is driven. Fuel usage for the truck, $f_{t}$, is measured at the average load of the truck, which yields an accurate measure of true fuel usage when fuel usage is linear in the truck's load (which is approximately true), the truck always carries the same amount per trip, the truck makes deliveries at a constant rate (e.g., the stores on the route are equally distant from each other), and the truck travels at the same speed during the trip (Kellner and Igl 2012). Fuel usage for the car, $f_{c}$, is insensitive to the load carried as the load for a car is generally a small fraction of the 
vehicle's total weight. The truck's load, $q_{t}$, is taken to be the legal carrying capacity for the truck, whereas the size of the car's load, $q_{c}$, reflects shopping habits more than a physical constraint. The cost of emissions, $p_{e}$, is assumed to be independent of the source of the emissions, which is accurate given the focus on carbon emissions: a kilogram of $\mathrm{CO}_{2}$ has the same impact if emitted by a car or a truck. We refer to $p_{e}$ as the "price of carbon". This cost is interpreted as the true cost of emissions including all externalities from other emitted gases or polutants. (See Currie and Walker (2011) for a discussion of other polutants due to vehicle traffic.) Depending on which objective is used to design the supply chain, it may or may not be included in the analysis.

It is useful to divide $c_{j}$ into two categories. The operating costs include variable costs and fuel consumption, i.e., $\left(v_{j}+f_{j} p_{j}\right) / q_{j}$. Emissions refers to the quantity of carbon emissions, $f_{j} e_{j} / q_{j}$, and emissions costs include the price of carbon, $f_{j} e_{j} p_{e} / q_{j}$.

Retail space is proportional to the amount of inventory the retailer holds in each store - doubling the amount of inventory doubles the needed foot print area of a store (holding the storage height constant). Thus, space costs are related to inventory quantities. Let $c_{s}$ be the retailer's space costs per unit per unit of time the unit is held in the store's inventory and let $t_{s}$ be the average time a unit spends in inventory at a store. (The subscript "s" refers to retail "space" throughout.) Hence, the retailer's cost of space per unit sold is $c_{s} t_{s}$. Neither the cost of inbound deliveries to the retailer nor warehouse space costs are considered in this analysis. The retailer sells durable goods, so the cost for spoilage or waste is not considered.

The space cost of inventory $\left(\$ k^{-1} \mathrm{yr}^{-1}\right)$ is also divided into several components:

$$
c_{s}=\frac{v_{s}+f_{s}\left(p_{s}+e_{s} p_{e}\right)}{q_{s}},
$$

where $v_{s}$ is the variable cost per unit of retail space per unit of time, $f_{s}$ is the amount of energy needed to maintain one unit of space for one unit of time, $p_{s}$ is the per unit price of energy, $e_{s}$ is the carbon emissions from each unit of energy and $q_{s}$ in the number of units of product stored per unit of retail space. The variable cost, $v_{s}$, primarily includes the cost of rent (which is generally quoted as a cost per unit of area per unit of time, such as $\$ m^{-2} y r^{-1}$ ), but it could also include the opportunity cost of capital or inventory obsolescence costs. The retailer uses energy primarily from two source: electricity for lighting, cooling and operating office equipment; and natural gas for heating. Thus, $f_{s}, p_{s}$ and $c_{s}$ are taken to be averages weighted by the relative usage of electricity and natural gas. This does not restrict other measures of energy which could be appropriate given the context. As before, operating costs include the variable and fuel consumption costs, and emissions are proportional to fuel consumption.

Let $C$ be the the average cost per unit sold $\left(\$ k^{-1}\right)$, which includes the average cost to transport 
a unit from the retailer's warehouse to a consumer's home as well as the cost of the space needed for the retail stores:

$$
C=c_{c} d_{c}+c_{t} d_{t}+c_{s} t_{s}
$$

If $p_{e}$ is the correct price of carbon and included in $c_{c}, c_{t}$, and $c_{s}$, then minimizing $C$ minimizes society's total cost. Minimizing $C$ is also an appropriate objective for the retailer when the retailer must compensate consumers for their travel costs. Pancras, Sriram and Kumar (2012) provide evidence that consumers do account for travel costs in their shopping decisions. The retailer provides this compensation to consumers by modifying its price - with a dense network of many stores the retailer charges a higher price because consumers are offered the convenience of a store near their home, but with a sparse network of few stores, the retailer charges a lower price to motivate consumers to travel the longer distance. In this formulation the price reduction is exactly one-for-one with any additional transportation costs incurred by the consumers, leaving aggregate demand constant.

If carbon is not charged, i.e., $p_{e}=0$, the the objective to "minimize $C$ " is equivalent to "minimize operating costs". Alternatively a "minimize emissions" objective could be adopted, which is equivalent to "minimize $C$ " under the assumption of a very high price for carbon (e.g., as $\left.p_{e} \rightarrow \infty\right)$.

Parts of the retail store density problem are familiar. Given a set of $n$ stores, the routing subproblem is the well-known Traveling Salesman Problem (TSP) - find a route through $n$ locations, starting and ending at the same location, and visiting each location exactly once so as to minimize the total transportation cost. There exists an extensive literature on heuristics and solutions to the TSP (see Bramel and Simchi-Levi 1997; Lawler, Lenstra, Rinnooy Kan and Shmoys 1985). More generally, there is a considerable literature on vehicle routing, such as when a fleet of vehicles (as opposed to a single vehicle) must be used to make deliveries to a set of known points in a region so as to minimize travel distances (e.g., Dantzig and Ramser 1959; Daganzo 1984; Haimovich and Rinnooy Kan 1985). This literature is further extended by work that includes inventory management along with vehicle routing (e.g., Federgruen and Zipkin 1984; Burns, Hall, Blumenfeld, Daganzo 1985; Gallego and Simchi-Levi 1990). The key differences between this supply chain design problem and the TSP and its extensions are (i) the retailer can choose the location of the stores and (ii) the retailer accounts for the consumers' transportation costs (i.e., the "final mile" of the supply chain is not ignored).

Focusing on just the consumers' transportation costs, the problem is analogous to the well known $k$-median problem (which is also referred to as the $p$-median problem or multi-source Weber problem or location-allocation problem). In the $k$-median problem there exists a set of 
demand locations. The objective is to choose $k$ locations - call them stores - to minimize the total transportation cost from the demand locations to their nearest store. The $k$ - median problem is generally studied in its discrete form (i.e., a finite number of possible demand and store locations) but there has also been some work on the continuous $k$-median problem, which is the retailer's supply chain design problem when the retailer's transportation and space costs are ignored (see Papadimitriou, 1981). Work on the $k$-median problem has focused on good solution procedures, rather than on the structure of the solution. See Daskin (1995) for an overview of the $k$-median problem. Brimberg, Hansen, Mladenović, Taillard (2000) study numerous solution algorithms for the discrete $k$-median problem and Fekete, Mitchell and Beurer (2005) do the same for the continuous version of the problem.

This combination of the TSP and the $k$-median problem has not been previously studied (with or without considering inventory/space). It extends the traditional boundary of supply chain analysis, which typically incorporates just the firm, to include the final leg of transportation performed by consumers.

There is some work on the interaction between operational decisions and emissions. Hoen, Tan, Fransoo and van Houtum (2010) analyze a single location inventory model in which the firm can select from a set of transportation modes that vary in their per unit delivery cost, level of emission and replenishment lead time. Benjaafar, Li and Daskin (2010) analyze a single location model in which inventory management decisions (the timing and quantity of orders) influence supply chain holding costs, backorder costs and emissions which include the following: (i) a fixed amount per unit held on average in inventory; (ii) a fixed amount per unit sold and (iii) a fixed amount per delivery. Unlike those two papers, this model has multiple locations. Unlike Hoen, Tan, Fransoo and van Houtum (2010), the retailer in this model has a single mode of transportation - the focus is on distances travelled rather than lead time. Unlike Benjaafar, Li and Daskin (2010), this model does not include a fixed amount of emissions per unit sold (this would not influence the decisions considered), and the amount of emissions per delivery is not fixed (it depends on the number of stores and their locations). Similar to Hoen, Tan, Fransoo and van Houtum (2010), this model finds that charging an explicit price for carbon emissions, unless unreasonably high, is unlikely to influence decisions enough to reduce emissions substantially. Gillerlain, Fry and Magazine (2011) also study a model in which a retailer and consumers incur transportation costs and emission costs based on distances. They too evaluate the cost minimizing number of stores, but they impose a different spacial geometry - in their model, stores and consumers are located on the boundary of a circle. They find that imposing a constraint on a retailer that limits its emissions may actually lead to an increase in total emissions (because the constraint on the retailer leads to higher consumer 
emissions). These papers consider the effectiveness of different methods for providing incentives to reduce emissions (e.g., taxes or constraints) but they do not measure the impact for failing to provide incentives.

Caro, Corbett, Tan and Zuidwijk (2011) consider a supply chain in which firms have the opportunity to make investments to reduce emissions. They do not explicitly consider store locations, replenishment routes or inventory. Instead, they study how different methods for allocating carbon emissions to various processes influences the amount of investment in emission reductions. Keskin and Plambeck (2011) also study carbon allocation rules and find that a poorly chosen rule may lead self interested firms to decisions that raise overall emissions. Ata, Lee and Tongarlak (2012) study the upstream structure of the fresh produce supply chain, holding the downstream structure (the number and location of stores) fixed.

There is a large literature on facility location problems (see Daskin 1995 and Snyder and Shen 2011) that generally focuses on the fixed cost of opening facilities and the transportation cost of serving a set of customers from the opened facilities. Mak and Shen (2010) review a number of studies that include inventory costs in the facility location problem: e.g., Shen, Coullard, and Daskin (2003); Shu, Teo, Shen (2005); and Shen and Qi (2007). A key insight from these models is that there exists is a tradeoff between location and economies of scale in inventory - fewer warehouses are more inventory efficient but that approach increases transportation costs because the warehouses are also further away from customers. The same well-known tradeoff regarding inventory and economies of scale exists in this model with retail stores - the more stores, the less inventory efficient they are as they capture less demand. However, this model is also different than those papers in several ways: whereas they allow the decision maker to assign a demand source to the non-closest warehouse (thereby allowing demand to be aggregated, but resulting in a combinatorial optimization problem), in this model customers (the demand sources) always choose the nearest store, so this option for aggregation is not available; they have a single level of transportation in the supply chain (between warehouses and stores), whereas this model considers the interaction between two transportation levels of the supply chain (inbound to stores and inbound to consumers' homes); and most importantly, they do not focus on the consequences for failing to consider critical costs within the supply chain (as in the consequence of ignoring emissions costs).

\section{Analysis}

The retail store density problem involves a number of related decisions, primarily store locations, replenishment routes and store sizing. This analysis first considers transportation costs and then 


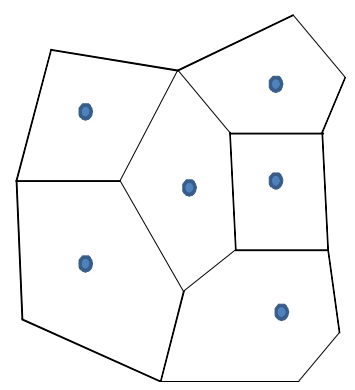

Figure 1: Voronoi diagram depicting the service regions for a six store configuration.
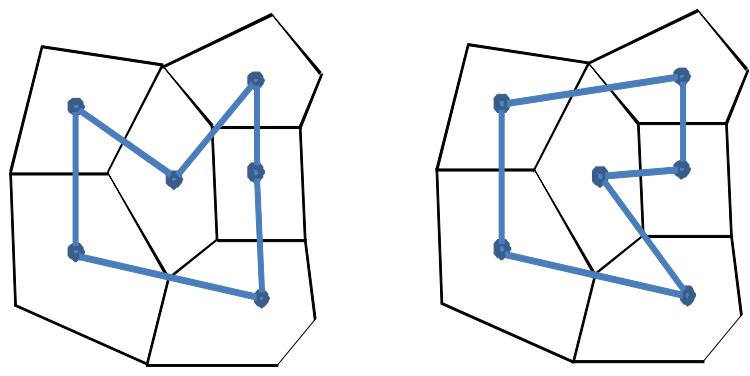

Figure 2: Two possible delivery routes through a configuration of six stores.

evaluates space costs.

Given a set of $n$ store locations, the region of customers over area $a$ can be partitioned into $n$ sub-regions that represent the stores' "service areas", i.e., the store is closer to all customers in its service area than any other store. This partitioning is also called a Voronoi diagram. Figure 1 displays one possible partitioning: In addition to store locations, the retailer must choose a TSP route to minimize its transportation costs. Figure 2 presents two possible routes in the Figure 1 partitioning.

The optimal locations for stores in the retail density problem is unknown and may involve a complex geometry. Figure 3 displays a tiling with equilateral triangles. There are two other feasible tilings that consist of a single regular polygon, one with squares and the other with hexagons. This paper assumes one of the these three tilings is implemented. Therefore, the resulting Voronoi diagram is a tessellation of a single regular polygon and all service regions have the same area. Carlsson (2012) considers additional tilings and finds that total transportation costs can be reduced with an Archimedean spiral relative to the three considered here. If the retailer's transportation and space costs are sufficiently low (so it is desirable to have many facilities) then he shows that the Archimedean spiral can reduce transportation costs relative to the triangle tiling by approximately $7 \%$. 


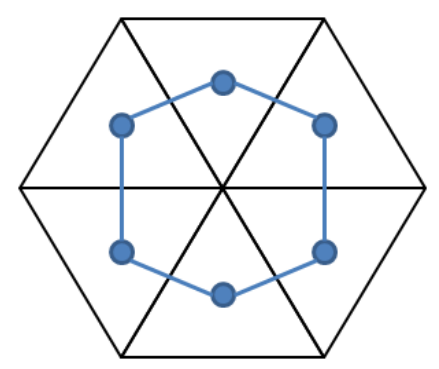

Figure 3: Triangle tessellation of stores

Within a store's service area, consumers have an average round trip distance of

$$
d_{c}=\phi_{c} n^{-1 / 2}
$$

where $\phi_{c}$ depends only on which tiling is selected and the area of the region, $a$. ( $\phi_{c}$ is proportional to $\sqrt{a}$.) The retailer's distance to deliver to all of the stores is

$$
d_{t}=\phi_{t} n^{1 / 2}
$$

where $\phi_{t}$ also depends only on which tiling is selected and the area $a$. ( $\phi_{t}$ is proportional to $\sqrt{a}$.) See the Appendix for the derivation of the above relationships. The consumer's travel distance equation assumes that all consumers in a store's service area indeed purchase from the store, i.e., the market is fully "covered". Market coverage can be relaxed without changing the qualitative insights of the model - market coverage is often optimal, and even if not, it is generally optimal to have near market coverage.

Now turn to the cost of retail space. Given that retail space is directly proportional to the amount of inventory held, an inventory model is needed. In this context the optimal policy to choose quantities and dispatches is unknown and likely complex. Heuristic policies in similar situations are developed by Cachon (2001) and Gürbüz, Moinzadeh and Zhou (2007), but their results do not provide closed form estimates of inventory levels. Hence, the approach taken here is to develop a tractable approximation of this inventory system.

Assume the retailer's truck is dispatched with $q_{t}$ units every $q_{t} / \lambda$ units of time, which is called a "period". Each store places an order every period and receives a replenishment with a zero lead time (or the lead time is sufficiently small relative to the period length that it can be effectively ignored). Each store operates with a base stock policy: order enough inventory to ensure that the store has $S$ units immediately after a delivery. For store $j$, let $\lambda_{j \tau}$ be its demand in period $\tau$, and let $I_{i \tau}$ be its inventory at the end of period $\tau$. There are no lost sales (i.e., demand can be backordered), so $I_{i \tau}<0$ is possible. As the retailer sells durable goods, there is also no spoilage. 
Furthermore, the offered product variety is held constant. It follows that

$$
I_{j, \tau+1}=I_{j \tau}+\left(\left(S-I_{j \tau}\right)^{+}+\omega_{j, \tau+t}\right)^{+}-\lambda_{j, \tau+1}
$$

where $\omega_{j \tau}$ is an adjustment to store $j$ 's order to ensure a full truck load delivery:

$$
\sum_{j=1}^{n} \omega_{j, \tau+1}=q_{t}-\sum_{j=1}^{n}\left(S-I_{j, \tau}\right)^{+} .
$$

For example, if the sum of the orders from the stores is less than a truckload, additional inventory is sent to fill the truck, and if orders exceed the truck's capacity, then some stores receive less than their order. This inventory policy is difficult to analyze primarily because the adjustment $\omega_{j \tau}$ may cause a delivery in one period to be more or less than demand in the previous period. However, if the store operates such that stockouts are rare and stores rarely start a period with more than $S$ units of inventory, then

$$
\begin{aligned}
E\left[I_{j}\right] & \approx S+E\left[\omega_{j}\right]-E\left[\lambda_{j}\right] \\
& \approx S-E\left[\lambda_{j}\right]
\end{aligned}
$$

because on-average the average adjustment is zero, $E\left[\omega_{j}\right]=0$. If demand is taken to be normally distributed, then $S=E\left[\lambda_{j}\right]+z \sigma_{j}$, where $\sigma_{j}$ is the standard deviation of a store's demand in one period and $z$ is a constant chosen by the firm to influence the service level (i.e., the probability of being in-stock at the end of a period). Thus,

$$
E\left[I_{j}\right]=z \sigma_{j}
$$

is an estimate of a store's inventory. Each store services an area $(1 / n)^{t h}$ of the total region and each period has $q_{t} / \lambda$ length of time, so

$$
\sigma_{j}=\sqrt{\frac{1}{n}} \sqrt{\frac{q_{t}}{\lambda}} \sigma=\sqrt{\frac{q_{t}}{n \lambda}} \sigma .
$$

(Recall, $\lambda$ and $\sigma$ are the mean and standard deviation of demand per unit of time.) The average time a unit spends in the retail store, $t_{s}$, is $n E\left[I_{j}\right] / \lambda$, so the average space cost per unit sold is

$$
c_{s} t_{s}=c_{s} \frac{n E\left[I_{j}\right]}{\lambda}=\phi_{s} c_{s} n^{1 / 2}
$$

where

$$
\phi_{s}=z \sqrt{\frac{q_{t}}{\lambda}}\left(\frac{\sigma}{\lambda}\right)
$$

There are three terms in the $\phi_{s}$ constant: inventory increases as the retailer chooses a higher service level $(z)$, or if deliveries become less frequent $\left(\sqrt{q_{t} / \lambda}\right.$ increases $)$ or if demand becomes more variable (the coefficient of variation of aggregate demand, $\sigma / \lambda$, increases). 
From (3), the inventory cost per unit grows proportional to $n^{1 / 2}$ : as more stores are added units stay in the store longer, thereby incurring greater space costs. This reflects the notion that there are statistical economies of scale in managing inventory: stores with larger service areas have higher inventory productivity because they experience demand with a lower coefficient of variation.

Combining the retail space costs, (3), with the transportation distances, (1) and (2), the supply chain cost function is

$$
C(n)=\phi_{c} c_{c} n^{-1 / 2}+\left(\phi_{t} c_{t}+\phi_{s} c_{s}\right) n^{1 / 2} .
$$

Considering only the transportation costs, the cost function $C(n)$ is consistent with several studies of probabilistic versions of the $k$-median and TSP problems. For example, Fisher and Hochbaum (1980) consider the $k$-median problem of selecting $n$ store locations from a set of randomly chosen sites to minimize the total distance consumers must travel to the closest of the $n$ stores. They find that the value of the optimal cost grows proportional to $\sqrt{1 / n}$, as in (4). For the TSP, Beardwood, Halton and Hammersley (1959) show that the shortest distance through $n$ randomly selected points in an unit area is asymptotically proportional to $\sqrt{n}$, again, as in (4).

Table 1 summarizes the transportation constants in the cost function.

Table 1: Distance coefficients for different tessellations for $a=1$

\begin{tabular}{lllll}
\hline \hline tessellation & $\phi_{c}$ & $\phi_{t}$ & $\phi_{c} \phi_{t}$ & $\phi_{c} / \phi_{t}$ \\
\hline triangle & 0.807293 & 0.877383 & 0.708 & 0.920 \\
square & 0.765196 & 1.000000 & 0.765 & 0.765 \\
hexagon & 0.754393 & 1.074570 & 0.811 & 0.702
\end{tabular}

For a given number of stores $(n)$ and a fixed region size, consumers prefer hexagons because the hexagon pattern has the lowest $\phi_{c}$. (Others have observed that the "honeycomb" pattern is effective for the $k$-median problem - Papadimitriou, 1981). The firm, on the other hand, travels the farthest with the hexagon tessellation. In all cases, consumers on average travel a shorter distance than the retailer $\left(\phi_{c}<\phi_{t}\right)$ despite the fact that some consumers must travel farther (e.g., as much as twice as far with the triangle tessellation). Consequently, if it were equally costly for consumers and the retailer to transport goods, then one would expect the optimal tessellation to have few stores, forcing consumers to drive long distances.

If $n$ is allowed to be non-integer, minimization of $C(n)$ is straightforward, given that it is quasi-convex in $n$. Let $n^{*}$ be the cost minimizing number of stores:

$$
n^{*}=\frac{\phi_{c} c_{c}}{\phi_{t} c_{t}+\phi_{s} c_{s}}
$$

From Table $1, \phi_{c} / \phi_{t}<1$, so $n^{*}>2$ only if $c_{c}>>c_{t}$, which is likely because the load carried by a truck is substantially larger than the load carried by a car, $q_{t}>>q_{c}$. Section 4 provides specific estimates to confirm that $c_{c}>c_{t}$. 
The minimum cost is

$$
C\left(n^{*}\right)=2\left(\phi_{c} c_{c}\right)^{1 / 2}\left(\phi_{t} c_{t}+\phi_{s} c_{s}\right)^{1 / 2} .
$$

If the cost of retail space is low (or ignored), then the triangle tessellation is best no matter the relative transportation costs, because, according to Table 1, that minimizes $\phi_{c} \phi_{t} \cdot{ }^{1}$ In fact, the transportation cost with the triangle tessellation is about $7 \%$ lower than with hexagons (1$\sqrt{0.708 / 0.811})$. It is also possible to show that for a single polygon of $s$ sides, $\phi_{c} \phi_{t}$ is decreasing for all $s \geq 3$, suggesting that the triangle tessellation may perform well even with tessellations that include more than one regular polygon. However, if the retailer's transportation costs are low (or ignored) relative to space costs, then the hexagon tessellation is best, as it minimizes $\phi_{c}$. In fact, when the retailer's transportation cost is ignored, for a fixed area of customers served, the optimal configuration has each store with a circular service area of customers - for a fixed area of uniformly distributed consumers, a circle minimizes the average distance consumers travel.

The distances $d_{c}$ and $d_{t}$ are measured by the Euclidian norm, $L_{2}$. Another common norm is $L_{1}$, which is sometime referred to as the "Manhattan" norm or the "city-block" norm in which the distance between points $\left\{x_{1}, y_{1}\right\}$ and $\left\{x_{2}, y_{2}\right\}$ is taken to be $\left|x_{2}-x_{1}\right|+\left|y_{2}-y_{1}\right|$, i.e., travel occurs along a square grid. It is possible to show that for consumers, even with the $L_{1}$ norm, their round-trip distance to the nearest store is proportional to $n^{-1 / 2}$. With the $L_{1}$ norm, the retailer's travel distance is easiest to estimate with the square tessellation, and in that case the distance continues to be proportional to $n^{1 / 2}$. Hence, these results do not appear to be sensitive to how distance is measured.

The solution $n^{*}$ minimizes total supply chain costs, only if the price of carbon, $p_{e}$, is fully charged to the retailer and consumers. There are a number of reasons why this may not incur, including the fact that a precise measure of $p_{e}$ is difficult to obtain. Hence, it is worthwhile to consider two alternative approaches for selecting a design for the downstream chain design. The first minimizes total emissions while ignoring explicit operating costs. In that case a design is chosen as if the cost of emissions is extremely high relative to operating costs (i.e., operating costs are dwarfed by emissions costs, so they can be effectively ignored). The second minimizes explicit operating costs while ignoring emission costs. That case is relevant if one believes emissions externalities are small or there is no explicit means in place that charges for carbon emissions. This can be taken to be the current status quo.

1 When exact values of the TSP are utilized (and retail space costs are ignored), then triangles are best (among the three) for $n=2$ and $n \geq 5$, hexagons are best for $n=3$ and squares are best for $n=4$. 
Let $C^{e}(n)$ be total emissions per unit,

$$
C^{e}(n)=\phi_{c} c_{c}^{e} n^{-1 / 2}+\left(\phi_{t} c_{t}^{e}+\phi_{s} c_{s}^{e}\right) n^{1 / 2},
$$

and $C^{o}(n)$ be total operating costs per unit,

$$
C^{o}(n)=\phi_{c} c_{c}^{o} n^{-1 / 2}+\left(\phi_{t} c_{t}^{o}+\phi_{s} c_{s}^{o}\right) n^{1 / 2},
$$

where, for $j \in\{c, t, s\}$,

and

$$
c_{j}^{e}=\frac{f_{j} e_{j}}{q_{j}},
$$

$$
c_{j}^{o}=\frac{v_{j}+f_{j} p_{j}}{q_{j}} .
$$

Note that $C^{e}(n)$ is not actually a cost, as it is total emissions, but for notational consistency it is represented with a "C" nevertheless.

As with $C(n)$, both $C^{e}(n)$ and $C^{o}(n)$ are quasi-convex and a cost minimizing $n$ can be found:

$$
n^{e}=\arg \min _{n} C^{e}(n)=\frac{\phi_{c} c_{c}^{e}}{\phi_{t} c_{t}^{e}+\phi_{s} c_{s}^{e}}, \quad \text { and } n^{o}=\arg \min _{n} C^{o}(n)=\frac{\phi_{c} c_{c}^{o}}{\phi_{t} c_{t}^{o}+\phi_{s} c_{s}^{o}} .
$$

As one would expect, as carbon becomes expensive, the optimal design approaches the emissions minimizing design, and as carbon becomes cheap, the optimal design approaches the operating cost minimizing design:

$$
\lim _{p_{e} \rightarrow \infty} n^{*}=n^{e}, \quad \text { and } \lim _{p_{e} \rightarrow 0} n^{*}=n^{o} .
$$

Further, the optimal design falls somewhere between the two extreme designs: $\min \left\{n^{o}, n^{e}\right\} \leq n^{*} \leq$ $\max \left\{n^{o}, n^{e}\right\}$.

Whether the emissions minimizing design is dense with stores $\left(n^{o}<n^{e}\right)$ or sparse with stores $\left(n^{e}<n^{o}\right)$ depends on the parameter values of the technologies. In particular, if $\gamma>1$, then the emissions minimizing design is dense with stores (because if $\gamma>1$ then $d n^{*} / d p_{e}>0$ ), where for $j \in\{c, t, s\}$,

$$
\gamma=\frac{\beta_{c}}{\frac{\delta_{t}}{\delta_{t}+\delta_{s}} \beta_{t}+\frac{\delta_{s}}{\delta_{t}+\delta_{s}} \beta_{s}}, \quad \beta_{j}=\frac{f_{j} e_{j}}{v_{j}+f_{j} p_{j}}=\frac{c_{j}^{e}}{c_{j}^{o}}, \quad \text { and } \delta_{j}=\frac{\phi_{j}\left(v_{j}+f_{j} p_{j}\right)}{q_{j}}
$$

The parameters $\beta_{j}$ and $\delta_{j}$ are introduced for notational convenience and are referred to as the emissions to operating cost ratios - they are the ratio of emissions to operating cost for one vehicle or unit of space for one unit of time, independent of the amount of product carried or stored (i.e., independent of $q_{j}$ ). For example, it is the emissions to move a car one $k m$ relative to the operating cost to move the car one $\mathrm{km}$. To summarize, minimizing emissions surely requires a denser network with more stores when $\beta_{c}>\max \left\{\beta_{t}, \beta_{s}\right\}$, but minimizing emissions does not always involve a denser network - when $\beta_{c}<\min \left\{\beta_{t}, \beta_{s}\right\}$, the emissions minimizing supply chain may have few stores because the consumers' cars have low emissions relative to their operating 
costs. This result contrasts with the intuition that because trucks are considerably more efficient at hauling goods than cars (on a $\$$ per $\mathrm{kg}$ per $\mathrm{km}$ basis), the emissions minimizing supply chain should surely be dense with stores (McKinnon and Woodburn 1994). That intuition is based on the assumption that each additional $\mathrm{km}$ driven by the truck replaces a $\mathrm{km}$ driven by a car. That is correct if consumers and stores are located exclusively on a line. In a linear world, moving a store closer to a consumer might swap one car $\mathrm{km}$ for a truck $\mathrm{km}$, thereby producing a substantial efficiency gain. But in a two dimensional world this one-for-one swapping is not possible - as the number of stores increases, each additional $\mathrm{km}$ traveled by truck replaces a smaller and smaller distance traveled by car.

Now consider the supply chain's emissions, operating costs and total costs with these different designs. Define the operating cost penalty for minimizing emissions as $C^{o}\left(n^{e}\right) / C^{o}\left(n^{o}\right)-1$ - this is the percentage increase in operating costs that a supply chain incurs when the emissions minimizing design is chosen. This provides a measure of the explicit cost to adopt a "minimize emissions" objective. Some algebra yields,

$$
\frac{C^{o}\left(n^{e}\right)}{C^{o}\left(n^{o}\right)}-1=\frac{1}{2}\left(\gamma^{1 / 2}+\gamma^{-1 / 2}\right)-1=\frac{1}{2}\left(\left(\frac{n^{e}}{n^{o}}\right)^{1 / 2}+\left(\frac{n^{e}}{n^{o}}\right)^{-1 / 2}\right)-1 .
$$

If $\gamma=1$, minimizing emissions also minimizes operating costs. This could occur in the unlikely case in which $\beta_{c}=\beta_{t}=\beta_{s}$. Otherwise, there generally is a penalty. The magnitude of this penalty can be bounded:

$$
\frac{C^{o}\left(n^{e}\right)}{C^{o}\left(n^{o}\right)} \leq \frac{1}{2} \max \left\{\left(\frac{\beta_{c}}{\beta_{t}}\right)^{1 / 2}+\left(\frac{\beta_{c}}{\beta_{t}}\right)^{-1 / 2},\left(\frac{\beta_{c}}{\beta_{s}}\right)^{1 / 2}+\left(\frac{\beta_{c}}{\beta_{s}}\right)^{-1 / 2}\right\}-1 .
$$

The bound provides intuition for when the penalty is small and when it might be large. In particular, if $\beta_{c} / \beta_{t}$ and $\beta_{c} / \beta_{s}$ are sufficiently close to 1 , the emissions penalty is small. However, the emissions penalty can be large if there is a large discrepancy between either $\beta_{c}$ and $\beta_{t}$ or between $\beta_{c}$ and $\beta_{s}$.

Define the emissions penalty for minimizing operating costs as $C^{e}\left(n^{o}\right) / C^{e}\left(n^{e}\right)$. This penalty is identical to the previous one considered, and shares the same penalty bound, (6):

$$
\frac{C^{e}\left(n^{o}\right)}{C^{e}\left(n^{e}\right)}=\frac{1}{2}\left(\gamma^{1 / 2}+\gamma^{-1 / 2}\right)-1=\frac{1}{2}\left(\left(\frac{n^{e}}{n^{o}}\right)^{1 / 2}+\left(\frac{n^{e}}{n^{o}}\right)^{-1 / 2}\right)-1
$$

Hence, if there is a small emissions penalty, then there is a small operating cost penalty and a large emissions penalty is always matched with a large operating cost penalty.

The next two penalties reflect the total cost penalty for adopting one of the extreme approaches of either minimizing just emissions or just operating costs:

$$
\frac{C^{*}\left(n^{o}\right)}{C^{*}\left(n^{*}\right)}=\frac{1}{2}\left(\left(\frac{n^{o}}{n^{*}}\right)^{1 / 2}+\left(\frac{n^{o}}{n^{*}}\right)^{-1 / 2}\right)-1 \quad \text { and } \quad \frac{C^{*}\left(n^{e}\right)}{C^{*}\left(n^{*}\right)}=\frac{1}{2}\left(\left(\frac{n^{e}}{n^{*}}\right)^{1 / 2}+\left(\frac{n^{e}}{n^{*}}\right)^{-1 / 2}\right)-1 .
$$


Refer to these as the total cost penalties. If the cost of carbon is extremely high or extremely low, then these total cost penalties approach the emissions and operating cost penalties:

$$
\lim _{p_{e} \rightarrow \infty} \frac{C^{*}\left(n^{o}\right)}{C^{*}\left(n^{*}\right)}=\lim _{p_{e} \rightarrow 0} \frac{C^{*}\left(n^{e}\right)}{C^{*}\left(n^{*}\right)}=\frac{C^{e}\left(n^{o}\right)}{C^{e}\left(n^{e}\right)}=\frac{C^{o}\left(n^{e}\right)}{C^{o}\left(n^{o}\right)} .
$$

\section{Parameter Estimates}

This section provides estimates for the parameters in the retail store density problem. The first objective is to determine if the emissions minimizing design has a denser network of smaller stores relative to the operating cost minimizing design (i.e., if $n^{e}>n^{o}$ ). The second objective is to determine the magnitude of the various penalties. Baseline estimates are given as well as several scenarios that indicate plausible ranges. The section ends with a discussion of options for reducing emissions.

Begin with the transportation parameters. The average mileage of passenger vehicles in the U.S. (in 2009) is 21.1 miles $\mathrm{gal}^{-1}$ or $8.97 \mathrm{~km} \mathrm{l}^{-1}$ (EPA 2009). Fuel consumption is then $f_{c}=1 / 8.97$ $=0.111 \mathrm{l} \mathrm{km}^{-1}$. A typical retailer truck travels 6 miles per gallon of diesel, which yields a fuel consumption of $f_{t}=0.392 \mathrm{l} \mathrm{km}^{-1} .^{2}$

From EPA (2005), $8.8 \mathrm{~kg}$ of $\mathrm{CO}_{2}$ are emitted per gallon of gasoline, or $e_{c}=2.325 \mathrm{~kg} \mathrm{CO}_{2}$ $l^{-1}$. From the same report $10.1 \mathrm{~kg}$ of $\mathrm{CO}_{2}$ are emitted per gallon of diesel, or $e_{t}=2.669 \mathrm{~kg} \mathrm{CO}_{2}$ $l^{-1}$. On May 21, 2012 the national average price per gallon of gasoline and diesel, respectively, were $p_{c}=0.98 \$ l^{-1}$ and $p_{t}=1.05 \$ l^{-1}$ (http://www.eia.gov/petroleum/gasdiesel/). For the variable operating cost of a car, Barnes and Langworthy (2003, Table 4.2) provide an estimate of $\$ 0.0644 \mathrm{~km}^{-1}$ in 2003 dollars. Adjusting for inflation of $2.5 \%$ per year, yields a 2012 estimate of $v_{c}=\$ 0.0804 \mathrm{~km}^{-1} \cdot{ }^{3}$ For trucks, the comparable estimates in Barnes and Langworthy (2003)

2 The Bureau of Transportation Statistics (2011) Table 4-14 reports that truck fuel consumption in the United States was 5.9 in 2004 but dropped to 5.4 by 2008. Bonney (2009) reports that Walmart's fuel efficiency in 2005 was 5.9 miles per gallon, which increased to 7.1 miles per gallon by 2008 .

3 The American Automobile Association (2011) suggests $v_{c}=\$ 0.0621 \mathrm{~km}^{-1}$ : the average cost per kilometer to drive a sedan includes $\$ 0.0278$ for maintenance, $\$ 0.006$ for tires, and $\$ 0.0283$ for distance related depreciation (in $\$ \mathrm{~km}^{-1}$ ) (Three observations are provided for the annual depreciation cost $\{10000, \$ 3471\},\{15000, \$ 3728\}$ and $\{20000, \$ 3924\}$, where the first term is the miles driven during the year and the second is the total depreciation cost. A linear regression through these observations yields a slope of $\$ 0.0453$ per mile, or $\$ 0.0283 \mathrm{~km}^{-1}$ ) 
are $\$ 0.1375 \mathrm{~km}^{-1}$ in 2003 dollars and the 2012 estimate of $\$ 0.172 \mathrm{~km}^{-1}$, which does not include driver wages. If driver wages are included, at $\$ 50,000$ per year and 100,000 miles, their estimate is $v_{t}=\$ 0.484 \mathrm{~km}^{-1}$.

McKinnon and Woodburn (1994) report that the average consumer in a survey carried $q_{c}=18$ $\mathrm{kg}$ of goods with each shopping trip. A retail truck can carry up to 45,000 $\mathrm{lbs}$ in the U.S., which is about $q_{t}=20,000 \mathrm{~kg}$. Even if consumers carried $40 \mathrm{kgs}$ per shopping visit, the retailer's truck carries a load that is 500 times greater. In terms of variable operating costs, the car incurs $v_{c}+f_{c} p_{c}=\$ 0.189 \mathrm{~km}^{-1}$, or $\$ 0.30$ per mile, and the truck incurs $v_{t}+f_{t} p_{t}=\$ 0.896 \mathrm{~km}^{-1}$, or $\$ 1.43$ per mile. Given that a truck has a variable operating costs per $\mathrm{km}$ that is less than 5 times that of a car, but carries at least 500 times more product, it follows that $c_{c}>>c_{t}$ : if the price of carbon is ignored $\left(p_{e}=0\right)$ and $q_{c}=18$ and $q_{t}=20,000$, then $c_{c}=\$ 0.0105 \mathrm{~km}^{-1}$ and $c_{t}=\$ 0.000045 \mathrm{~km}^{-1}$, yielding a ratio of $c_{c} / c_{t}=235$. Table 2 summarizes the transportation parameters.

Table 2: Baseline transportation parameters

\begin{tabular}{llllll}
\hline \hline & $f_{j}$ & $e_{j}$ & $v_{j}$ & $p_{j}$ & $q_{j}$ \\
\hline Consumer cars $(j=" c ")$ & 0.111 & 2.325 & 0.0804 & 0.98 & 18 \\
Retailer truck $(j=" t ")$ & 0.392 & 2.669 & 0.484 & 1.05 & 20,000 \\
\hline Units are $f_{j}=l \mathrm{~km}^{-1} ; e_{j}=k g \mathrm{CO}_{2} l^{-1} ; v_{j}=\$ \mathrm{~km}^{-1} ; p_{j}=\$ l^{-1} ; q_{j}=k g$ &
\end{tabular}

To consider alternative scenarios, it is not necessary to vary the emissions per liter for gasoline and diesel, $e_{c}$ and $e_{t}$, because these are estimated with little error. It is possible that future fuel efficiency could change. For example, current U.S. standards require that automobile manufacturers achieve 54.5 miles per gallon among the cars in their fleet by 2025 (Vlasic 2011), which would represent a $158 \%$ improvement over the 2009 level. Three additional scenarios can be constructed in which consumer fuel efficiency doubles, retail fuel efficiency doubles, or both double. Increasing fuel efficiency (decreasing $f_{t}$ ) is analogous to increasing variable operating costs (because $\beta_{j}=e_{j} /\left(v_{j} / f_{j}+p_{j}\right)$, cutting fuel usage in half is the same as doubling variable operating costs). The final parameters are the cost of gasoline, $p_{c}$, and diesel, $p_{t}$. Substantial asymmetries in these two prices have not occurred historically, but they do vary considerably. Suppose both could increase by a factor of $2: p_{c}=1.96$ and $p_{t}=2.10$. Table 3 lists the emissions to operating cost ratios for five scenarios.

The estimate $v_{c}=\$ 0.0837 \mathrm{~km}^{-1}$ is comparable. The AAA focuses on the first five years of vehicle life, so it is expected to underestimate the variable cost of operating the existing fleet, which has an average age of approximately 10.8 years (Meier 2012). 
Table 3: Transportation emissions to operating cost ratios, $\beta_{c}$ and $\beta_{t}{ }^{*}{ }^{*}$

\begin{tabular}{lll}
\hline \hline Scenario & $\beta_{c}$ & $\beta_{t}$ \\
\hline Baseline & 1.364 & 1.168 \\
High consumer (car) fuel efficiency: $f_{c} / 2$ & 0.957 & 1.168 \\
High retailer (truck) fuel efficiency: $f_{t} / 2$ & 1.364 & 0.758 \\
High consumer and retailer fuel efficiency: $f_{c} / 2, f_{t} / 2$ & 0.957 & 0.758 \\
High fuel prices: $2 p_{c}, 2 p_{t}$ & 0.866 & 0.800 \\
\hline${ }^{*}$ Fuel efficiency scenarios double fuel efficiency and the high fuel scenario doubles the price of gasoline and diesel
\end{tabular}

Now consider the retail space parameters: $v_{s}, f_{s}, p_{s}$, and $e_{s}$. The cost of retail space, $v_{s}$, varies considerably by the quality and type of the location - according to loopnet.com, among the top 20 metropolitan areas in the United States, in March 2012, the average retail lease space was $\$ 19.8$ per square foot per year, with a low of $\$ 12.26$ (Detroit) and a high of $\$ 36.46$ (San Francisco). Retail space in a successful shopping mall, can be considerably higher, as in $\$ 50$ per square foot per year (Whitaker 2012). For the baseline scenario, take $\$ 19.8$ per square foot per year, which is $v_{s}=\$ 212.85 m^{-2} y_{r}^{-1}$

Table 4 provides electricity and natural gas usage by type of retailer in the United States. The average February 2012 price of electricity to commercial customers in the U.S. was $\$ 0.101 k W h^{-1}$ (Table 5.6.A. Average Retail Price of Electricity to Ultimate Customers by End-Use Sector, by State, February 2012 and 2011). The price of natural gas for commercial firms has ranged from $\$ 5$ to $\$ 15$ per 1000 cubic feet over the period of 1984-2012, with a February 2012 average of $\$ 7.97$ (http://www.eia.gov/dnav/ng/hist/n3020us3m.htm). For the baseline scenario, combine these prices with the average mercantile consumption levels reported in Table 4 to yield $f_{s} p_{s}=$ $206.6 \times 0.101+248.9 \times 0.00797=\$ 22.85 m^{-2} y^{-1}$.

Table 4: Electricity and natural gas usage by retail type

\begin{tabular}{lllll}
\hline \hline & \multicolumn{3}{c}{ Mercantile } & \\
\cline { 2 - 4 } & Non-mall & Mall & All & Food Sales \\
\hline Electricity $\left(k W h \mathrm{~m}^{-2} \mathrm{yr}^{-1}\right)$ & 154.2 & 240.0 & 206.6 & 522.8 \\
Natural gas $\left(\mathrm{ft}^{3} \mathrm{~m}^{-2} \mathrm{yr}^{-1}\right)$ & 222.4 & 264.0 & 248.9 & 327.9 \\
\hline Source: Energy Information Administration, 2003 & Commerical Buildings Energy Consumption \\
Survey: Table C1A
\end{tabular}

From eGRID2012 Version (1.0) (year 2009 data), average U.S. emissions is $0.55 \mathrm{~kg} \mathrm{CO} \mathrm{kWh}^{-1}$. The lowest emissions region has $0.23 \mathrm{~kg} \mathrm{CO}_{2} \mathrm{kWh}^{-1}$ (Upstate NY) and the highest has $0.83 \mathrm{kgCO}$ $k W h^{-1}$ (Rockies). Natural gas emits $0.05 \mathrm{kgs} \mathrm{CO}_{2} \mathrm{ft}^{-3}$ (EPA emissions calculator 2012). For the baseline scenario, combine the U.S. average electricity emissions and the natural gas emissions with the average mercantile consumption levels reported in Table 4 to yield $f_{s} e_{s}=206.6 \times 0.55+$ $248.9 \times 0.05=126.1 \mathrm{~kg} \mathrm{CO}_{2} \mathrm{~m}^{-2} \mathrm{yr}^{-1}$.

Table 5 provides baseline and alternative scenarios for the parameters relevant to $\beta_{s}$. In all 
cases, natural gas emissions are taken to be $0.05 \mathrm{kgs} \mathrm{CO}_{2} \mathrm{ft}^{-3}$, the price of electricity is $\$ 0.101$ $k W h^{-1}$ and the price of natural gas is $\$ 7.97$ per 1000 cubic feet. The "low electricity emissions" scenarios corresponds to the emissions of the lowest emissions region in the U.S. $\left(0.23 \mathrm{~kg} \mathrm{CO}_{2}\right.$ $\left.k W h^{-1}\right)$ and the "high electricity emissions" scenario corresponds to the highest emissions region $\left(0.83 \mathrm{~kg} \mathrm{CO} \mathrm{KWh}^{-1}\right)$. Clean energy could be produced locally by the retailer, as in roof solar panels, or more distant renewable power, as in hydro-electric production. Clean electricity could also be produced by carbon capture and storage technology - see İşlegen and Reichelstein (2011). The "high rent" scenarios double the cost to rent per square meter per year relative to the baseline (to approximately $\$ 40$ per square foot per year). The "high fuel usage" scenarios correspond to the usage of Food Sales retailers (i.e., groceries), which are higher in large part due to the need for product refrigeration.

Table 5: Retail space baseline and alternative scenarios for parameters that yield $\beta_{s}$

\begin{tabular}{lllll}
\hline \hline Scenarios & $v_{s}$ & $f_{s} e_{s}$ & $f_{s} p_{s}$ & $\beta_{s}$ \\
\hline Baseline & 212.8 & 126.1 & 22.9 & 0.535 \\
Low electricity emissions intensity & 212.8 & 60.0 & 22.9 & 0.254 \\
High electricity emissions intensity & 212.8 & 183.9 & 22.9 & 0.780 \\
High rent & 425.7 & 126.1 & 22.9 & 0.281 \\
Low electricity emissions intensity and high rent & 425.7 & 60.0 & 22.9 & 0.134 \\
High fuel usage & 212.8 & 304.0 & 55.4 & 1.133 \\
High fuel usage and high rent & 425.7 & 304.0 & 55.4 & 0.632 \\
\hline$v_{s}=\$ m^{-2} \mathrm{yr}^{-1} ; f_{s} e_{s}=\mathrm{kg} \mathrm{CO}_{2} \mathrm{~m}^{-2} \mathrm{yr}^{-1} ; f_{s} p_{s}=\$ \mathrm{~m}^{-2} \mathrm{yr}^{-1} ; \beta_{s}=\mathrm{kgCO}_{2} \$^{-1}$ \\
"Low electricity emissions intensity" corresponds to 0.23 $\mathrm{kg} \mathrm{CO2} \mathrm{per} \mathrm{kWh}^{-1}$ "High electricity emissions intensity" \\
corresponds to 0.83 kg CO2 per kWh. "High rent" doubles the rent per square meter per year. "High fuel usage" \\
corresponds to the usage of Food Sales retailers listed in Table 4.
\end{tabular}

The remaining parameters to estimate are part of $\delta_{t}$ and $\delta_{s}$. As the cost per $k g$ due to trucking is considerably less than the cost of car transportation or physical space, assume a hexagon tessellation is adopted. (The qualitative results presented are the same for the triangle or square tessellations.) As distances are measured in kilometers, let $a=10,000 \mathrm{~km}^{2}$ : the retailer serves a region that is of the order of magnitude of $100 \mathrm{~km}$ by $100 \mathrm{~km}$. It follows that $\phi_{c}=75.4$ and $\phi_{t}=107.5$. To evaluate $\phi_{s}$, use $z=2.5$ (which corresponds to a $99.4 \%$ in-stock probability), $\lambda=7 \times q_{t} \mathrm{~kg} \mathrm{wk}^{-1}$ (which implies one delivery per day) and $\sigma / \lambda=0.1$ (which is the coefficient of variations for total demand in the region over one week) $: \phi_{s}=2.5 \times \sqrt{1 / 7} \times 0.1=0.0945 . \quad q_{s}$ is a challenging parameter to estimate as it is the $\mathrm{kg}$ of product per $\mathrm{m}^{2}$. Using 2011 data from Walmart, $q_{s}=141 \mathrm{~kg} \mathrm{~m}^{-2}{ }^{4}$. Hence, using baseline estimates for $v_{s}$ and $f_{s} p_{s}$, yields $\delta_{s}=0.16$, which is 33 times larger than $\delta_{t}$.

4 In 2011, Walmart's annual inventory turns were 8.75. U.S. sales revenue was $\$ 309 \mathrm{~B}$. Hence, U.S. inventory (in sales $\$$ s) was $\$ 309 \mathrm{~B} / 8.75=\$ 35.3 \mathrm{~B}$. U.S. square footage of retail space was $698 \mathrm{M}$, so Walmart held $\$ 35.3 \mathrm{~B} / 698 \mathrm{M}=\$ 50.59$ of inventory per square foot. From 
It seems reasonable to conclude, even with some substantial estimation error in $q_{s}$ and the other parameters, that $\delta_{s}>>\delta_{t}$.

The first issue to address is whether the emissions minimizing supply chain is more dense with smaller stores than the operating cost minimizing supply chain, i.e., is $n^{e}>n^{o}$ ? Taking $\delta_{s}>>\delta_{t}$, this occurs if $\beta_{c}>\beta_{s}$. Comparing Tables 3 and 5 , that holds for the baseline scenarios, and occurs for most combinations of scenarios with the exception of high consumer fuel efficiency $\left(\beta_{c}=0.957\right)$ and high retailer space fuel usage $\left(\beta_{s}=1.13\right)$. Thus, the emissions minimizing supply chain generally has more stores, located closer to consumers, than the supply chain that minimizes operating costs. This is particularly true if the retailer has lower electricity emissions and high rent $\left(\beta_{s}=0.133\right)$. In those cases, a retailer that minimize operating costs builds large stores that are far from customers (to economize on its high rent costs) whereas a retailer that minimizes emissions builds many small stores close to customers (to exploit its clean electricity). Table 6 indicates that the emissions minimizing supply chain may have many more stores, upwards of nine times more, than the operating cost minimizing supply chain

Table 6: Ratio of the number of stores that minimize emissions to number that minimize operating costs, $n^{e} / n^{o}$

\begin{tabular}{llllll}
\hline \hline Scenarios & Baseline & $f_{c} / 2$ & $f_{t} / 2$ & $f_{c} / 2, f_{t} / 2$ & $2 p_{c}, 2 p_{t}$ \\
\hline Baseline & 2.5 & 1.7 & 2.5 & 1.8 & 1.6 \\
Low electricity emissions intensity & 4.8 & 3.4 & 5.1 & 3.6 & 3.1 \\
High electricity emissions intensity & 1.7 & 1.2 & 1.7 & 1.2 & 1.1 \\
High rent & 4.6 & 3.2 & 4.8 & 3.3 & 3.0 \\
Low electricity emissions intensity and & 9.1 & 6.4 & 9.7 & 6.8 & 5.8 \\
high rent & & & & & \\
High fuel usage & 1.2 & 0.8 & 1.2 & 0.9 & 0.8 \\
High fuel usage and high rent & 2.1 & 1.5 & 2.2 & 1.5 & 1.4 \\
\hline
\end{tabular}

Now turn to the evaluation of the penalty bound, (6). Considering just the transportation parameters, $\beta_{c}$ and $\beta_{t}$, the bound for the baseline scenario is remarkably small, about $0.3 \%$ :

$$
\frac{1}{2}\left(\left(\frac{1.364}{1.168}\right)^{1 / 2}+\left(\frac{1.364}{1.168}\right)^{-1 / 2}\right)-1=0.003 .
$$

Recall, this applies to the operating cost penalty for minimizing emissions, the emissions penalty for minimizing operating costs and the total cost penalty. This penalty with respect to transportation costs is small because cars and trucks have similar emissions to operating cost ratios: $\beta_{c}=1.364$

their website, they report that they made $4 \mathrm{M}$ deliveries to their stores, which implies $\$ 309 \mathrm{~B} / 4 \mathrm{M}$ $=\$ 77,250$ per delivery. Given 20,000 $\mathrm{kg}$ per delivery implies $\$ 77,250 / 20,000 \mathrm{~kg}=\$ 3.86$ $\mathrm{kg}^{-1}$. Walmart then has $\$ 50.59 \mathrm{sqft} \mathrm{t}^{-1} / \$ 3.86 \mathrm{~kg}^{-1}=13.1 \mathrm{~kg} \mathrm{sqft}^{-1}$. With $10.76 \mathrm{sqft} \mathrm{m}^{-2}$, there is $10.76 \times 13.1=141 \mathrm{~kg} \mathrm{~m}^{-2}$. 
for cars and $\beta_{t}=1.168$ for trucks. There is a larger discrepancy between these ratios in the other transportation scenarios described in Table 3, but even in the scenario with the largest discrepancy (high retailer fuel efficiency), the bound is still only $4.3 \%$. Thus, from the perspective of transportation costs, the supply chain design is remarkably robust given reasonable parameters. If emissions are minimized while operating costs are ignored, operating costs will nevertheless not increase by much (e.g., by $0.3 \%$ in the baseline scenario). Similarly, if operating costs are minimized while emissions costs are ignored, total emissions increase by the same relatively small amount. The same finding is observed even if consumers can choose their shopping frequency (see the Appendix for details).

It is important to note that this robustness result does not occur for all parameters. According to the penalty bound, (6), there is a substantial penalty whenever there is an asymmetry in the emissions to operating cost ratios. It happens to be that those ratios are similar for cars and trucks. Furthermore, the substantial difference in loads carried, which one might presume would create an asymmetry that leads to a large penalty, has no role in the penalty bound - the substantial difference in the loads carried is accounted for no matter which objective is selected, and thus they do not factor into the penalty bound.

The transportation robustness result is reminiscent of the well-known robustness result for the EOQ problem. In the EOQ problem, costs are the sum of two terms, one linearly increasing in the decision variable, call it $x$, and the other decreasing in the inverse of $x$ (i.e., it is $1 / x$ ). In the retail store density problem, costs are again the sum of two terms, but now one is linearly increasing in $\sqrt{x}$ and the other decreasing in the inverse of $\sqrt{x}$. It has been established that the EOQ problem has a flat objective function (see Dobson 1988, Porteus 2002), but it follows that the objective function in the retail store density problem is even flatter. Nevertheless, even with a relatively flat function, a poorly chosen decision can lead to a substantial increase in costs. In particular, in the EOQ problem, if one parameter is grossly misestimated, then the cost penalty can essentially be unlimited. In the retail store density problem this does not occur - the penalty bound is finite, and can be small, even if the true cost of carbon is enormous yet ignored in the decision. The reason is that erring in the cost of carbon causes errors in multiple parameters. For example, if the cost of emissions from gasoline are ignored, so is the cost of emissions from diesel. Given that the emissions to operating cost ratios for cars and trucks are similar, these errors can net out, thereby leading to nearly optimal decisions for the system.

Considering the retailer's space cost, Table 7 evaluates the penalty bounds for each scenario and Table 8 reports that actual penalties. A comparison between Tables 7 and 8 reveals that the bound is reasonably tight and corresponds well to the actual penalty. We observe a somewhat 
substantial penalty, $10.3 \%$, for the baseline scenario. This is due to the asymmetry in the emissions to operating cost ratios for cars, $\beta_{c}=1.36$, and for retailer space, $\beta_{s}=0.534$. The penalties in the other scenarios vary considerably, depending on how the $\beta_{s}$ and $\beta_{c}$ parameters change relative to each other. The highest penalty with the baseline transportation parameters (and the 2nd highest in the sample of 35 scenarios), $67.4 \%$, occurs when the retailer uses electricity from a low emissions source (nearly comparable to renewable energy) and operates in an environment with high retail space costs. Hence, in this situation outcomes are considerably different depending on the selected objective. If operating costs are minimizing while ignoring emissions, then emissions are $67.4 \%$ higher than their minimal level. Similarly, if emissions are minimizing while ignoring operating costs, then operating costs are $67.4 \%$ higher than their lowest level. In this scenario there is a clear tension between environmental and financial preferences - as long as there is no explicit charge for carbon (so that carbon costs are not part of minimizing operating costs), one cannot have both low operating costs and low emissions. To put a $67.4 \%$ emissions penalty in perspective, it would represent for Walmart about 24 million metric tonne $\mathrm{CO}_{2}$ per year, which exceeds their current target of reducing their annual emissions in their supply chain by 20 million metric tonnes. ${ }^{5}$

Table 7: Emissions and operating cost penalty bounds

\begin{tabular}{llllll}
\hline \hline Scenarios & Baseline & $f_{c} / 2$ & $f_{t} / 2$ & $f_{c} / 2, f_{t} / 2$ & $2 p_{c}, 2 p_{t}$ \\
\hline Baseline & $11.2 \%$ & $4.3 \%$ & $11.2 \%$ & $4.3 \%$ & $2.9 \%$ \\
Low electricity emissions intensity & $37.4 \%$ & $22.8 \%$ & $37.4 \%$ & $22.8 \%$ & $19.4 \%$ \\
High electricity emissions intensity & $3.9 \%$ & $0.5 \%$ & $4.3 \%$ & $0.7 \%$ & $0.1 \%$ \\
High rent & $32.8 \%$ & $19.4 \%$ & $32.8 \%$ & $19.4 \%$ & $16.3 \%$ \\
Low electricity emissions intensity and & $75.4 \%$ & $52.5 \%$ & $75.4 \%$ & $52.5 \%$ & $46.9 \%$ \\
high rent & & & & & \\
High fuel usage & $0.4 \%$ & $0.5 \%$ & $4.3 \%$ & $0.7 \%$ & $0.9 \%$ \\
High fuel usage and high rent & $7.5 \%$ & $2.2 \%$ & $7.5 \%$ & $2.2 \%$ & $1.2 \%$ \\
\hline
\end{tabular}

5 With the baseline transportation parameters and the "low electricity emissions intensity and high rent" scenario for retail space, the operating cost minimizing supply chain emits $0.75 \mathrm{~kg} \mathrm{CO} 2$ per $\mathrm{kg}$ of product sold, whereas the emissions minimizing supply chain emits $0.45 \mathrm{~kg}$ $\mathrm{CO}_{2}$ per $\mathrm{kg}$ of product sold. Walmart is estimated to sell in the United States 20,000 $\mathrm{kg}$ per delivery x $4 \mathrm{M}$ deliveries per year $=80 \mathrm{~B} \mathrm{~kg}$ per year. A savings of $0.3 \mathrm{kgCO} 2$ per $\mathrm{kg}$ x $80 \mathrm{~B} \mathrm{~kg}$ $=24 \mathrm{M}$ metric tonnes of $\mathrm{CO}_{2}$. If the baseline scenario is taken for retail space, there is a potential reduction of $0.06 \mathrm{~kg} \mathrm{CO} 2$ per $\mathrm{kg}$ of product sold, which would be $5.2 \mathrm{M}$ metric tonnes of $\mathrm{CO}_{2}$, 
Table 8: Operating cost and emissions penalties

\begin{tabular}{llllll}
\hline \hline Scenarios & Baseline & $f_{c} / 2$ & $f_{t} / 2$ & $f_{c} / 2, f_{t} / 2$ & $2 p_{c}, 2 p_{t}$ \\
\hline Baseline & $10.3 \%$ & $3.8 \%$ & $10.9 \%$ & $4.1 \%$ & $2.7 \%$ \\
Low electricity emissions intensity & $32.8 \%$ & $19.3 \%$ & $35.3 \%$ & $21.2 \%$ & $16.6 \%$ \\
High electricity emissions intensity & $3.7 \%$ & $0.5 \%$ & $3.9 \%$ & $0.5 \%$ & $0.1 \%$ \\
High rent & $30.8 \%$ & $17.8 \%$ & $32.0 \%$ & $18.7 \%$ & $15.1 \%$ \\
Low electricity emissions intensity and & $67.4 \%$ & $46.1 \%$ & $71.5 \%$ & $49.4 \%$ & $41.3 \%$ \\
high rent & & & & & \\
High fuel usage & $0.4 \%$ & $0.4 \%$ & $0.5 \%$ & $0.3 \%$ & $0.8 \%$ \\
High fuel usage and high rent & $7.3 \% \%$ & $2.0 \%$ & $7.5 \%$ & $2.1 \%$ & $1.2 \%$ \\
\hline
\end{tabular}

Given the potential tension between financial and environmental preferences, a natural solution is to include an explicit charge for carbon emissions into the financial objective function - with an explicit price for carbon, i.e., $p_{e}>0$, the negative externalities associated with carbon emissions can be properly accounted for in the supply chain design that minimizes operating costs (which now include a portion of the cost of carbon emissions). Estimates of $p_{e}$ vary considerably, but generally fall in the range between $\$ 20$ and $\$ 1000$ per metric tonne (see Tol 2008). How large does $p_{e}$ have to be to induce substantial reductions in emissions in the context of the retail store density problem? Ideally, a small fee for carbon would induce a sufficiently dramatic shift in the supply chain that a large portion of the potential emissions reduction can be achieved. Unfortunately, this does not appear to be the case. To explain, define the emissions gap reduction as the percentage of the potential emissions reduction that is achieved when carbon is explicitly priced, i.e., when $p_{e}>0$. In particular, the emissions gap reduction is

$$
\frac{C^{e}\left(n^{o}\right)-C^{e}\left(n^{*}\left(p_{e}\right)\right)}{C^{e}\left(n^{o}\right)-C^{e}\left(n^{e}\right)}:
$$

the denominator is the reduction in emissions that occurs with a switch from minimizing operating costs to minimizing emissions, and the numerator is the amount of carbon reduced as the price of carbon is increased from zero to $p_{e}$. Figure 4 plots the emissions gap reduction curve for two scenarios: in the first the baseline parameters are used for both transportation and space, whereas in the second the baseline parameters for transportation are paired with the "low electricity emissions intensity and high rent" scenario for retail space. In the first case the maximum reduction in carbon emissions is $10.3 \%$ whereas in the second it is $67.4 \%$. The figure demonstrates that the gap is reduced at a decreasing rate in the price of emissions - that is the good news, as the initial price increase for carbon has the largest effect. Unfortunately, a substantially high carbon price is needed to close the emissions gap by a significant amount. For example, if the price of carbon is $\$ 100$ per metric tonne, which is at the upper limit of most estimates, then the emissions gap reductions are $16 \%$ and $11 \%$ in the two scenarios. To achieve a $90 \%$ emissions gap reduction requires a carbon 


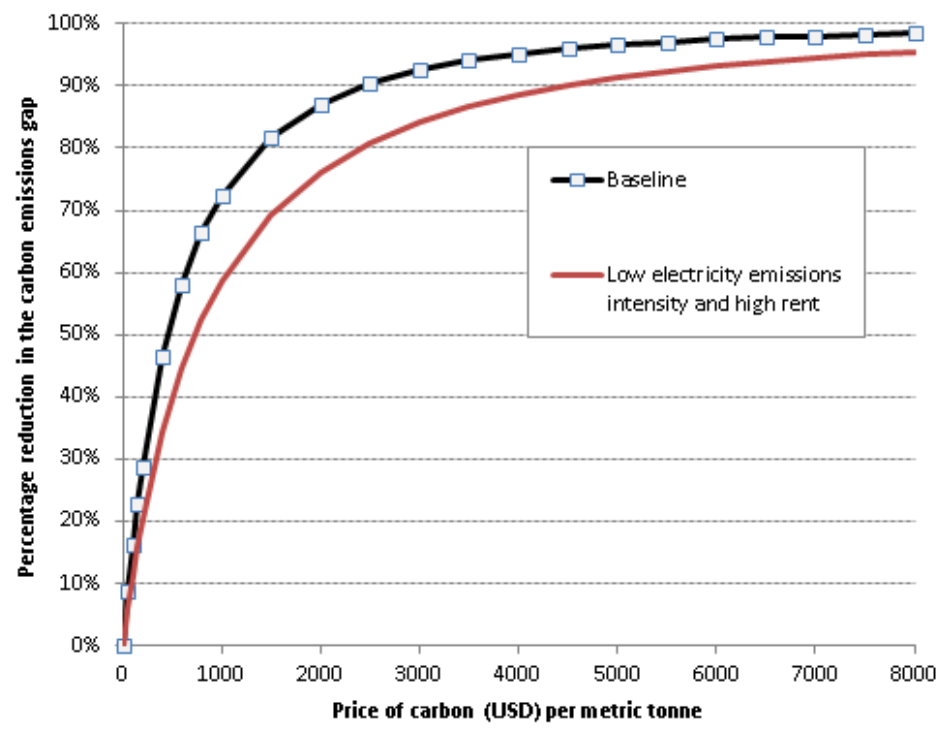

Figure 4: Emissions gap reduction - the percentage of the possible reduction in emissions achieved through an explicit price on carbon.

price of approximately $\$ 2,500$ and $\$ 4,500$ per metric tonne. To put these numbers in perspective, $\$ 1000$ per metric tonne, corresponds to a fee of $\$ 8.8$ per gallon of gasoline and $\$ 0.55$ per $\mathrm{kWh}$ for electricity (at the U.S. average emissions rate), which would increase the cost of gasoline by $337 \%$ (to $\$ 12.50$ per gallon) and increase the average cost of electricity by $645 \%$ (to $\$ 0.651$ per $k W h$ ). The conclusion from this observation is that while charging for carbon can induce a supply chain design that reduces emissions, very high (and quite possibly unreasonably high) prices are needed to achieve substantial reductions in emissions. Of course, an important caveat is that this analysis assumes constant technologies. A carbon tax could induce investments in technologies to reduce emissions. The impact of technological change is considered shortly.

Even though the model suggests that pricing carbon will not be an effective strategy for reducing emissions (because very high prices are needed to have a significant impact), there are alternative strategies to reduce emissions. Land use regulations that restrict the size of retail stores will force retailers to build networks with more stores, closer to consumers. As indicated earlier, the supply chain that minimizes emissions generally has considerably more, smaller stores, than the supply chain that minimizes operating costs. Alternatively, technological improvements in fuel usage or emissions can lead to substantial reductions in carbon emissions.

Table 9 provides total emission reductions that occur due to various improvements to the system assuming the baseline parameters as the starting point. The "short term" column assumes the supply chain design does not change before and after the improvement, on the assumption that 
supply chain design changes take time to implement. The "long term" column evaluates the emissions reduction after the improvement changes the supply chain design as well (i.e., the number of stores adjusts). In all cases the objective is to minimize supply chain operating costs and there is no price for carbon, $p_{e}=0$. The table reveals that changing consumer behavior (large quantities per shopping trip) or improving consumer fuel efficiency are the most effective strategies for reducing emissions. The short term impact of these changes are the most substantial, but even the long term changes are significant. The long term benefit of these consumer improvements is dampened relative to the short term because they induce a supply chain with fewer, larger stores - taken to the extreme, if consumers drove near zero-emissions vehicles, then the supply chain that minimizes emissions has one very large store located very far from customers, which mitigates some of the benefit of the low emissions vehicle.

Improvements in fuel efficiency could be achieved via a carbon tax to motivate automobile manufacturers to improve the efficiency of the vehicles they offer and to motivate consumers to choose those improved vehicles. However, this could also be achieved by regulation mandating higher fuel efficiency, such as the current requirement that automobile manufacturers achieve 54.5 miles per gallon among the cars in their fleet by 2025 (Vlasic 2011). Doubling the load consumers carry (which is equivalent to reducing their shopping frequency in half), appears to be more challenging to achieve through direct policy measures. For example, consumers would shop less frequently if fuel prices are higher, but, based on the delivery frequency model described in the appendix, doubling their purchase quantities would require more than a four-fold increase in fuel prices. (The purchase quantity is proportional to the square root of the cost of fuel, so at least a four fold increase in fuel is needed to double the purchase quantity.)

Table 9: Total supply chain emissions reductions under various improvements

\begin{tabular}{lll}
\hline \hline & \multicolumn{2}{c}{ Total emissions reduction } \\
\hline Double consumer load: $q_{c} \rightarrow 2 q_{c}$ & Short term & Long term \\
Double consumer fuel efficiency: $f_{c} \rightarrow \frac{1}{2} f_{c}$ & $35.6 \%$ & $29.3 \%$ \\
Double truck fuel efficiency: $f_{t} \rightarrow \frac{1}{2} f_{t}$ & $0.9 \%$ & $33.5 \%$ \\
Half retailer electricity usage: $f_{s} \rightarrow \frac{1}{2} f_{s}$ & $12.2 \%$ & $1.0 \%$ \\
Half retailer electricity emissions: $e_{s} \rightarrow \frac{1}{2} e_{s}$ & $12.2 \%$ & $13.4 \%$ \\
\hline
\end{tabular}

Reducing retailer electricity usage or emissions intensity provides the next largest set of reductions in emissions. Now the long term impact is even greater in the case of electricity usage because the improvement encourages additional stores, but only marginally so. Usage reductions could be achieved by subsidizing low energy use lighting (e.g., CFL or LEDs) and emissions intensity reductions could be achieved by subsidizing the purchasing or building of renewable power.

While improving truck fuel efficiency does reduce emissions, it does so only marginally because 
trucks are already considerably more efficient than cars. Improvements in truck fuel efficiency may be more beneficial in long-haul deliveries to the retailer, which are outside the scope of this model.

To emphasize a point again, the retail store density problem incurs a high penalty when there is an asymmetry in the emissions to operating cost ratios, $\beta_{j}$. This suggests that other forms of asymmetry could lead to substantial penalties. For example, suppose the cost of carbon is fully charged to consumers and the retailer (probably through higher energy prices). If everyone fully acknowledges these costs in their decisions, they will behave as if $c_{c}$ and $c_{t}$ are the costs to haul one $\mathrm{kg}$ of product one $\mathrm{km}$ for the consumer's car and the retailer's truck respectively. Furthermore, the retailer will recognize that $c_{s}$ is the cost to store one $\mathrm{kg}$ of product for one unit of time. The retailer has a strong incentive to fully acknowledge these costs and to make appropriate decisions. However, possibly due to cognitive limitations, consumers may not fully consider their transportation costs in their shopping decisions. Specifically, say consumers behave as if their costs are $\alpha_{c} c_{c}$ to transport one $\mathrm{kg}$ one $\mathrm{km}$, where $\alpha_{c} \in(0,1]$, yet the retailer fully accounts for its costs, and knows that consumers do not fully account for their costs. (See Attari, Dekay, Davidson and Bruine de Bruin 2010 for further discussion of consumer perception of energy expenditure and potential savings.) The optimal store configuration with $\alpha_{c}<1$ has

$$
\bar{n}\left(\alpha_{c}\right)=\frac{\alpha_{c} \phi_{c} c_{c}}{\phi_{t} c_{t}+\phi_{s} c_{s}}=\alpha_{c} n^{*} .
$$

Thus, if consumers partially ignore the costs of driving to a store, then the retailer builds a sparser network than optimal (i.e., stores that are too big), which requires consumers to drive farther than optimal. The cost penalty is then

$$
\frac{C\left(\bar{n}\left(\alpha_{c}\right)\right)-C\left(n^{*}\right)}{C\left(n^{*}\right)}=\frac{\alpha_{c}^{-1 / 2}+\alpha_{c}^{1 / 2}}{2}-1 .
$$

If consumers account for only $50 \%$ of their costs $\left(\alpha_{c}=0.5\right)$, the penalty is $6 \%$, but it increases to $34 \%$ if they account for only $20 \%$ of their actual costs $\left(\alpha_{c}=0.2\right)$ and $134 \%$ if they account of only $5 \%$ of their costs $\left(\alpha_{c}=0.05\right)$.

\section{Conclusion}

The retail store density problem involves choosing the size and location of retail stores in a region of consumers so as to minimize the sum of the retailer's inbound replenishment costs, the retailer's space costs and the consumers' travel costs. These costs include variable operating costs, such as wear and tear on vehicles, fuel, and rent and electricity for retail space. These costs could also reflect the externalities associated with carbon emissions, presumably in the form of higher fuel 
and electricity prices. However, it is possible (and maybe even likely) that the full cost of carbon emissions is not included in current energy prices.

Two extreme objectives are considered for the retail store density problem: (i) minimize operating costs, ignoring any possible cost associated with emissions and (ii) minimize emissions, ignoring operating costs. There are cases in which the retail store density problem is insensitive to which of those objectives is chosen - emissions are nearly minimized even if the objective is to minimize operating costs, and operating costs are nearly minimized even if the objective is to minimize emissions. For example, this insensitivity to the chosen objective occurs when retail space costs are low (or ignored), when the retailer uses electricity from a high emissions source or when the retailer's fuel usage (electricity and natural gas) is high. In each case, this result occurs because the sources of emissions (cars, truck, retail space) have similar carbon emissions to operating cost ratios. For example, even though trucks can haul several orders of magnitude more product than a car, the ratio of carbon emissions per $\mathrm{km}$ to variable operating costs per $\mathrm{km}$ is about the same for trucks and cars $\left(1.168 \mathrm{kgCO} \mathrm{CO}^{-1}\right.$ v.s. $\left.1.364 \mathrm{~kg} \mathrm{CO}_{2} \$^{-1}\right)$.

There are situation, however, when emission to operating cost ratios differ. For example, if the retailer operates in a high rent area and uses electricity from relatively clean sources, then its emissions to operating cost ratio for space differs considerably from the same ratio for cars $(0.134$ $\mathrm{kgCO} \mathrm{CO}_{2} \$^{-1}$ v.s. $1.364 \mathrm{kgCO} \mathrm{S}^{-1}$ ). In that case, the retail supply chain that minimizes operating costs consists of a sparse network to exploit the inventory productivity advantage of large stores while the retail supply chain that minimizes emissions consists of a dense network of small stores to exploit the retailer's "clean" electricity relative to the consumers' "dirty" vehicles. In fact, the supply chain that minimizes emissions has more than 9 times more stores than the supply chain that minimizes operating costs. Furthermore, minimizing operating costs increases emissions by $67.4 \%$ while minimizing emissions yields the same penalty on operating costs.

In situations in which there is a substantial difference in the structure of the retail supply chain that minimizes operating costs relative to the one that minimizes emissions, it is natural to consider the value of explicitly charging a price for carbon emissions. If carbon is explicitly charged, then it becomes part of operating costs, so the objective of minimizing operating costs begins to consider the quantity of emissions. Furthermore, using the retail store density model, it is possible to estimate how large a price needs to be imposed on carbon so that the downstream supply chain approaches one that minimizes emissions. Unfortunately, that price is considerably higher than most estimates of the cost of carbon, well over $\$ 1,000$ per metric tonne (Tol, 2008). Put another way, hefty prices need to be imposed on carbon to induce changes that are substantial enough to lead to a significantly lower emissions through changes in the structure of the downstream supply 


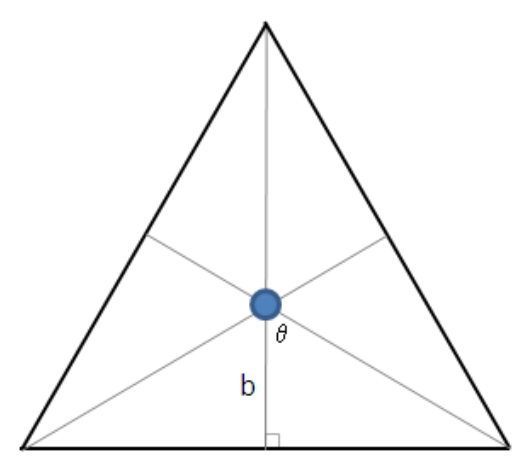

Figure 5: Sub-regions within a store's single service area given a triangle tesselation

chain. In this context, a carbon price is probably not an effective mechanism for change.

Taxing carbon is not the only approach to influence change. The retail supply chain that minimizes emissions generally has a dense network of small stores located close to consumers. Hence, land use regulations could be considered to limit the construction of large format retail stores. Technological improvement and changed in behavior provide other opportunities. However, fuel efficiency improvements for trucks has little impact on overall emissions and while substantial emissions reductions are possible by increasing the load consumers carry per store visit, it is not clear how to achieve that behavioral change without a blunt instrument (i.e., without imposing a controversially large tax). More promising, the model indicates that substantial reductions are possible by reducing retailer electricity consumption (e.g., more efficient lighting) or emissions (e.g., through renewable energy sources). The best option identified is to double consumer fuel efficiency, which is technologically feasible, and this would reduce emissions by about one third.

\section{Appendix A. Distances traveled}

To evaluate the average distance consumers travels, consider one of the service regions for a store. Within that region create a tessellation of right triangles by connecting the store to each vertex and to each face via a line perpendicular to its edge, to form sub-regions. Figure 5 demonstrates this for the triangle tessellation.

In a regular polygon with $s$ sides, an " $s$-gon", there are $2 s$ sub-regions. Consider one of the (identical) sub-regions. Let $\theta$ be the degree measure (in radians) of the acute angle formed at the vertex where the store is located and let $b$ be the shortest distance to the edge of the sub-region (i.e., $b$ is the height of one of the right triangles in Figure 5 ). For an $s$-gon, $\theta=\pi / s$. The average round-trip distance of customers within a sub-region to the store is:

$$
d_{c}(b, \theta)=2 \frac{\int_{0}^{b} \int_{0}^{y \tan \theta} \sqrt{x^{2}+y^{2}} d x d y}{(1 / 2) b^{2} \tan \theta}
$$


where the denominator is the area of the sub-region. Using a change of variables $(t=y / x)$, we obtain

$$
d_{c}(b, \theta)=(2 / 3)\left(\sqrt{1+(\tan \theta)^{2}}+\ln \left(\tan \theta+\sqrt{1+(\tan \theta)^{2}}\right) \tan ^{-1} \theta\right) b .
$$

The area of the service region is $a / n$ and the area of the sub-region is then $a /(2 s n)$. Thus, $(1 / 2) b^{2} \tan \theta=a /(2 s n)$, and $d_{c}(b, \theta)$ can be written as

$$
d_{c}=\phi_{c} n^{-1 / 2}
$$

where $\phi_{c}$ is a constant that depends on the tessellation (i.e., the number of sides, $s$ ) and the overall size of the region, $a$ :

$$
\phi_{c}=(2 / 3) \sqrt{a /(s \tan \theta)}\left(\sqrt{1+(\tan \theta)^{2}}+\ln \left(\tan \theta+\sqrt{1+(\tan \theta)^{2}}\right) \tan ^{-1} \theta\right)
$$

The retailer's truck must travel into and out of each region at least once (assuming there are at least two stores, $n \geq 2$ ). The truck's minimum distance within a sub-region is $2 b$, so the length of the TSP tour is no shorter than $2 b n$. Hence, a lower bound estimate for the retailer's transport distance is

$$
d_{t}=\phi_{t} n^{1 / 2}
$$

where the constant $\phi_{t}$ also only depends on the chosen tessellation and the area of the region, $a$ :

$$
\phi_{t}=2 \sqrt{a /(s \tan \theta)}
$$

The estimate $(2)$ is exact for triangles with $n \in\{2,6,10, \ldots\}$, for squares with $n \in\{2,4,6, \ldots\}$ and for all $n$ with hexagons. With triangles an upper bound on the TSP distance is $2 b(n+1)$, which is exact for $n \in\{4,8,12, \ldots\}$. For $n \in\{3,5,7,9, \ldots\}$ the TSP distance is $2 b(n+\sqrt{3}-1)$. With squares, the TSP distance is $2 b(n+\sqrt{2}-1)$ for odd $n$.

\section{Appendix B. Delivery frequency}

In the main model, consumers do not change the frequency of their store visits, i.e., $q_{c}$ is fixed. Now suppose consumers choose $q_{c}$. Consequently, each consumer visits a store every $q_{c} / \lambda_{c}$ units of time, where $\lambda_{c}$ is the consumer's consumption rate. The retailer continues to choose the number of stores, their locations and their size while operating a truck that holds $q_{t}$ units and makes deliveries every $q_{t} / \lambda$ units of time. This section evaluates the operating cost penalty when choices are made to minimize emissions. The emissions penalty when operating costs are minimized is analogous.

For consumer, the choice of $q_{c}$ involves a tradeoff between the cost of bringing goods to their home and the cost of storage - as $q_{c}$ increases, the consumer needs more storage space but shops less frequently. Let $h_{c}$ be the cost per unit of time to maintain the space to store one unit. The average storage cost is $h_{c} q_{c}$ per unit of time. (The analysis is qualitatively unchanged if based on 
average inventory.) Divide $h_{c}$ into two components, $h_{c}=h_{c}^{o}+h_{c}^{e} p_{e}$, where $h_{c}^{o}$ is the non-emissions related cost per unit of space per unit of time and $h_{c}^{e}$ is the amount of emissions per unit of space per unit of time (e.g., due to heating and cooling).

Consider the $q_{c}$ choice for consumer $i$, whose round-trip distance to the nearest store is $d_{i}$. As before, the consumer incurs cost $c_{c} d_{i}$ per unit purchased. Hall (1992) considers a different model that also includes a fixed cost for each delivery that is proportional to the distance travelled. It is convenient to write $c_{c}=\hat{c}_{c} / q_{c}$, where

$$
\hat{c}_{c}=v_{c}+f_{c}\left(p_{c}+e_{c} p_{e}\right)
$$

Further divide $\hat{c}_{c}$ into two components, $\hat{c}_{c}=\hat{c}_{c}^{o}+\hat{c}_{c}^{e}$, where

$$
\hat{c}_{c}^{o}=v_{c}+f_{c} p_{c}, \quad \hat{c}_{c}^{e}=f_{c} e_{c}
$$

Note that

$$
\beta_{c}=\hat{c}_{c}^{e} / \hat{c}_{c}^{o}
$$

Similarly, define

$$
\beta_{h}=h_{c}^{e} / h_{c}^{o}
$$

Suppose $q_{c}$ is chosen to minimize the consumer's average operating cost per unit, $C_{c}^{o}\left(q_{c}\right)$ :

$$
\min _{q_{c}} C_{c}^{o}\left(q_{c}\right)=\frac{h_{c}^{o} q_{c}}{\lambda_{c}}+\frac{\hat{c}_{c}^{o} d_{i}}{q_{c}}
$$

The cost minimizing quantity is $q_{c}^{o *}=\sqrt{\left(\hat{c}_{c}^{o} \lambda_{c} / h_{c}^{o}\right) d_{i}}$, and the resulting minimum operating cost is proportional to the square root of the round trip distance, $\sqrt{d_{i}}$

$$
C_{c}^{o}\left(q_{c}^{o *}\right)=2 \sqrt{\left(\hat{c}_{c}^{o} h_{c}^{o} / \lambda_{c}\right) d_{i}}
$$

If instead of minimizing operating costs, the consumer uses $q_{c}^{e *}=\sqrt{\left(\hat{c}_{c}^{e} \lambda_{c} / h_{c}^{e}\right) d_{i}}$, which minimizes the consumer's emissions, then operating costs are again proportional to $\sqrt{d_{i}}$ :

$$
C_{c}^{o}\left(q_{c}^{e *}\right)=\sqrt{\left(\hat{c}_{c}^{o} h_{c}^{o} / \lambda_{c}\right) d_{i}}\left(\sqrt{\frac{h_{c}^{o} \hat{c}_{c}^{e}}{\hat{c}_{c}^{o} h_{c}^{e}}}+\sqrt{\frac{\hat{c}_{c}^{o} h_{c}^{e}}{h_{c}^{o} \hat{c}_{c}^{e}}}\right) .
$$

Now evaluate costs across all consumer. Let $\hat{d}_{c}(b, \theta)$ be the average square root round-trip distance across all consumers in a sub-area of a store's service area in which the sub-area has height $b$ and angle $\theta$ :

$$
\hat{d}_{c}(b, \theta)=\sqrt{2} \frac{\int_{0}^{b} \int_{0}^{y \tan \theta}\left(x^{2}+y^{2}\right)^{1 / 4} d x d y}{(1 / 2) b^{2} \tan \theta} .
$$


Using a change of variables $(t=y / x)$, and $a /(2 s n)=(1 / 2) b^{2} \tan \theta$, we obtain

$$
\begin{aligned}
\hat{d}_{c}(b, \theta) & =\left(\frac{4 \sqrt{2}}{5} \frac{\int_{0}^{\tan \theta}\left(1+t^{2}\right)^{1 / 4} d t}{\tan \theta}\right) b^{1 / 2} \\
& =\left(\frac{4 \sqrt{2}}{5} \int_{0}^{\tan \theta}\left(1+t^{2}\right)^{1 / 4} d t\right) \tan \theta^{-5 / 4}\left(\frac{a}{s}\right)^{1 / 4} n^{-1 / 4}
\end{aligned}
$$

Define

$$
\hat{\phi}_{c}=\frac{4 \sqrt{2}}{5}(\tan \theta)^{-5 / 4}(a / s)^{1 / 4} \int_{0}^{\tan \theta}\left(1+t^{2}\right)^{1 / 4} d t .
$$

Thus the average costs across all consumers are

$$
\begin{aligned}
C_{c}^{o}\left(q_{c}^{o *}\right) & =2 \hat{\phi}_{c} \sqrt{\left(\hat{c}_{c}^{o} h_{c}^{o} / \lambda_{c}\right)} n^{-1 / 4} \\
C_{c}^{o}\left(q_{c}^{e *}\right) & =\left(\sqrt{\frac{h_{c}^{o} \hat{c}_{c}^{e}}{\hat{c}_{c}^{o} h_{c}^{e}}}+\sqrt{\frac{\hat{c}_{c}^{o} h_{c}^{e}}{h_{c}^{o} \hat{c}_{c}^{e}}}\right) \hat{\phi}_{c} \sqrt{\left(\hat{c}_{c}^{o} h_{c}^{o} / \lambda_{c}\right)} n^{-1 / 4}
\end{aligned}
$$

Now consider operating costs as a function of $n$, given consumers either implement the operating cost minimizing quantity, $q_{c}^{o *}$, or the emissions minimizing quantity, $q_{c}^{e *}$ :

$$
\begin{aligned}
& \hat{C}^{o}\left(q_{c}^{o *}, n\right)=2 \hat{\phi}_{c}\left(h_{c}^{o} \hat{c}_{c}^{o} / \lambda_{c}\right)^{1 / 2} n^{-1 / 4}+\left(\phi_{t} c_{t}^{o}+\phi_{s} c_{s}^{o}\right) n^{1 / 2} \\
& \hat{C}^{o}\left(q_{c}^{e *}, n\right)=\left(\sqrt{\frac{h_{c}^{o} \hat{c}_{c}^{e}}{\hat{c}_{c}^{o} h_{c}^{e}}}+\sqrt{\frac{\hat{c}_{c}^{o} h_{c}^{e}}{h_{c}^{o} \hat{c}_{c}^{e}}}\right) \hat{\phi}_{c}\left(h_{c}^{o} \hat{c}_{c}^{o} / \lambda_{c}\right)^{1 / 2} n^{-1 / 4}+\left(\phi_{t} c_{t}^{o}+\phi_{s} c_{s}^{o}\right) n^{1 / 2}
\end{aligned}
$$

The optimal $n$ to minimize operating costs is

$$
n^{o *}=\left(\frac{\hat{\phi}_{c}\left(h_{c}^{o} \hat{c}_{c}^{o} / \lambda_{c}\right)^{1 / 2}}{\phi_{t} c_{t}^{o}+\phi_{s} c_{s}^{o}}\right)^{4 / 3}
$$

and the choice to minimize emissions takes a similar form:

$$
n^{e *}=\left(\frac{\hat{\phi}_{c}\left(h_{c}^{e} \hat{c}_{c}^{e} / \lambda_{c}\right)^{1 / 2}}{\phi_{t} c_{t}^{e}+\phi_{s} c_{s}^{e}}\right)^{4 / 3}
$$

The minimum operating cost is

$$
\hat{C}^{o}\left(q_{c}^{o *}, n^{o *}\right)=3 \hat{\phi}_{c}^{2 / 3}\left(h_{c}^{o} \hat{c}_{c}^{o} / \lambda_{c}\right)^{1 / 3}\left(\phi_{t} c_{t}^{o}+\phi_{s} c_{s}^{o}\right)^{1 / 3}
$$

but if the emissions minimizing choices are taken, then operating costs are

$$
\begin{aligned}
\hat{C}^{o}\left(q_{c}^{e *}, n^{e *}\right)= & \left(\sqrt{\frac{h_{c}^{o} \hat{c}_{c}^{e}}{\hat{c}_{c}^{o} h_{c}^{e}}}+\sqrt{\frac{\hat{c}_{c}^{o} h_{c}^{e}}{h_{c}^{o} \hat{c}_{c}^{e}}}\right) \hat{\phi}_{c}\left(h_{c}^{o} \hat{c}_{c}^{o} / \lambda_{c}\right)^{1 / 2}\left(\frac{\hat{\phi}_{c}\left(h_{c}^{e} \hat{c}_{c}^{e} / \lambda_{c}\right)^{1 / 2}}{\phi_{t} c_{t}^{e}+\phi_{s} c_{s}^{e}}\right)^{-1 / 3} \\
& +\left(\phi_{t} c_{t}^{o}+\phi_{s} c_{s}^{o}\right)\left(\frac{\hat{\phi}_{c}\left(h_{c}^{e} \hat{c}_{c}^{e} / \lambda_{c}\right)^{1 / 2}}{\phi_{t} c_{t}^{e}+\phi_{s} c_{s}^{e}}\right)^{2 / 3}
\end{aligned}
$$


The operating cost penalty for minimizing emissions is (after some algebra)

$$
\begin{aligned}
\frac{\hat{C}^{o}\left(q_{c}^{e *}, n^{e *}\right)}{\hat{C}^{o}\left(q_{c}^{o *}, n^{o *}\right)}-1= & \frac{1}{3}\left[\left(\frac{\beta_{h}}{\beta_{c}}\right)^{-2 / 3}\left(\frac{\beta_{c}}{\beta_{t} \frac{\delta_{t}}{\delta_{t}+\delta_{s}}+\beta_{s} \frac{\delta_{s}}{\delta_{t}+\delta_{s}}}\right)^{-1 / 3}\right. \\
& +\left(\frac{\beta_{h}}{\beta_{c}}\right)^{1 / 3}\left(\frac{\beta_{c}}{\beta_{t} \frac{\delta_{t}}{\delta_{t}+\delta_{s}}+\beta_{s} \frac{\delta_{s}}{\delta_{t}+\delta_{s}}}\right)^{-1 / 3} \\
& \left.+\left(\frac{\beta_{h}}{\beta_{c}}\right)^{1 / 3}\left(\frac{\beta_{c}}{\beta_{t} \frac{\delta_{t}}{\delta_{t}+\delta_{s}}+\beta_{s} \frac{\delta_{s}}{\delta_{t}+\delta_{s}}}\right)^{2 / 3}\right]-1
\end{aligned}
$$

As before, the emissions to operating cost ratios are critical for determining the penalty, including the ratio for consumer space, $\beta_{h}$. The following table presents actual penalties for the main model's baseline scenario and various $\beta_{h}$ values. When $\beta_{h}=1$ the penalties are similar to those obtained in the main model (with $q_{c}$ fixed). Penalties generally increase as $\beta_{h}$ increases, as is expected: if the emissions to operating cost ratio for consumer space deviates considerably from 1, there will be a substantial difference between $q_{c}^{e *}$ and $q_{c}^{o *}$, which can lead to a large penalty. Nevertheless, the order of magnitude remains about the same even if $\beta_{h}$ deviate considerably from 1 .

Table 10: Operating cost penalties when customers choose their shopping frequency: baseline scenario for transportation parameters

\begin{tabular}{llll}
\hline \hline Scenarios & $\beta_{h}=1$ & $\beta_{h}=1.5$ & $\beta_{h}=2$ \\
\hline Baseline & $7.4 \%$ & $11.4 \%$ & $16.2 \%$ \\
Low electricity emissions intensity & $28.1 \%$ & $37.4 \%$ & $46.1 \%$ \\
High electricity emissions intensity & $2.5 \%$ & $4.2 \%$ & $7.6 \%$ \\
High rent & $26.1 \%$ & $34.9 \%$ & $43.3 \%$ \\
Low electricity emissions intensity and & $65.0 \%$ & $81.4 \%$ & $95.5 \%$ \\
high rent & & & \\
High fuel usage & $0.8 \%$ & $0.7 \%$ & $2.7 \%$ \\
High fuel usage and high rent & $5.0 \% \%$ & $8.0 \%$ & $12.2 \%$ \\
\hline
\end{tabular}

\section{References}

American Automobile Association. 2011. Your driving costs: how much are you really paying to drive? http://www.aaaexchange.com/Assets/Files/201145734460.DrivingCosts2011.pdf

Arrow, K. J. 2007. Global climate change: a challenge to policy. The Economists' Voice. 4(3).

Ata, B., D. Lee, M.H. Tongarlak. 2012. Got local food? HBS working paper.

Attari, S., M.L. DeKay, C.I. Davidson, W. Bruine de Bruin. 2010. Public perceptions of energy consumption and savings. PNAS. 107(37). 16054-16059.

Baumol, W. 1972. On taxation and the control of externalities. The American Economic Review. 62. 307-322. 
Beardwood, J., J.H. Halton, J.M. Hammersley, J. M. 1959. The shortest path through many points. Proc. Cambridge Philos. Soc. 55 299-327.

Benjaafar, S., Y. Li., M. Daskin. 2010. Carbon footprint and the management of supply chains: insights from simple models. Working paper. University of Minnesota.

Bonney, J. 2009. Size, scale, innovation. Always. The Journal of Commerce. Oct 19.

Bramel, J., D. Simchi-Levi. 1997. The Logic of Logistics: Theory, Algorithms, and Applications for Logistics Management. Springer Series in Operations Research. P. Glynn. S. Robinson, eds. Springer. New York.

Brimberg, J., P. Hansen, N. Mladenović, E. Taillard. 2000. Improvement and comparison of heuristics for solving the uncapacitated multisource Weber problem. Oper. Res. 48. 444-460.

Bureau of Transportation Statistics. 2011. National Transportation Statistics. U.S. Department of Transortation.

Burns, L.D., R.W. Hall., D.E. Blumenfeld, C.F. Daganzo. 1985. Distribution strategies that minimize transportation and inventory costs. Oper. Res. 33. 469-490.

Cachon, G. 2001. Managing a retailer's shelf space, inventory and transportation. MESOM. 3(3). 211-229.

Carlsson, J. G. 2012. Minimizing emissions in facility location. University of Minnesota working paper.

Caro, F., C. Corbett, T. Tan, R. Zuidwijk. 2011. Carbon-optimal and carbon-neutral supply chains. UCLA working paper.

Cline, W. 1992. The Economics of Global Warming. Institute for International Economics. Washington, D.C.

Currie, J., R. Walker. 2011. Traffic congestion and infant health: Evidence from E-ZPass. American Economic Review: Journal of Applied Economics. 3(1) 65-90.

Daganzo, C. 1984. The distance traveled to visit N points with a maximum of C stops per vehicle: an analytical model and an application. Transportation Science. 4. 331-350.

Dantzig, G.B., J.H. Ramser. 1959. The truck dispatching problem. Management Science. 6. 80-91.

Daskin, M.S.. 1995. Network and Discrete Location: Models, Algorithms, and Applications. John Wiley \& Sons Ltd. New York.

Department of Energy. 2011a. Weekly Retail On-Highway Diesel Prices. http://www.eia.gov/oog/ info/wohdp/diesel_detail_report_combined.asp 
Department of Energy. 2011b. Retail Gasoline Historical Prices. http://www.eia.gov/oil_gas/ petroleum/data_publications/wrgp/mogas_history.html

Dobson, G. 1988. Sensitivity of the EOQ to parameter estimates. Oper. Res. 36(4). 570-574.

Duany, A., J. Speck. 2010. Sprawl: an old cause of new problems. The Washington Post. October $16,2010$.

Environmental Protection Agency. 2005. Emission factors: average carbon dioxide emissions resulting from gasoline and diesel fuel. Document EPA420-F-05-001.

Environment Protection Agency. 2009a. Frequently asked questions about global warming and climate change: back to basics. Document EPA-430-R08-016.

Environment Protection Agency. 2009b. Light-duty automotive technology, carbon dioxide emissions, and fuel economy trends: 1975 through 2009. Document EPA420-S-09-001.

Environmental Protection Agency. 2011. Inventory of U.S. greenhouse gas emissions and sinks: 1990-2009. Document EPC 430-R-11-005. Table ES-2.

Federgruen, A., P. Zipkin. 1984. A combined vehicle routing and inventory allocation problem. Oper. Res. 32. 1019-1037.

Fekete, S., J. Mitchell., K. Beurer. On the continuous Fermat-Weber problem. Oper. Res. 53. 61-76.

Fisher, M., D.S. Hochbaum. 1980. Probabilistic analysis of the planar k-median probkem. Mathematics of Oper. Res. 5. 27-34.

Gallego, G., D. Simchi-Levi. 1990. On the effectiveness of direct shipping strategy for the onewarehouse multi-retailer R-system. Management Science. 36. 240-243.

Gillerlain, Z., M. Fry, M. Magazine. 2011. Supply chain design, tiple bottom line profit, and carbon mitigation. working paper. University of Cincinnati.

Glaeser, E. 2011. Triumph of the City: How Our Greatest Invention Makes Us Richer, Smarter, Greener, Healthier, and Happier. Penguin Group. New York.

Gürbüz, M.C., K. Moinzadeh, Y.P. Zhou. 2007. Coordinated Replenishment Strategies in Inventory/Distribution Systems. Management Science. 53(2). 293-307.

Haimovich, M., A.H.G. Rinnooy Kan. 1985. Bounds and heuristics for capacitated routing problems. Mathematics of Oper. Res. 10. 527-542.

Hoen, K.M.R., T. Tan, J.C. Fransso, G.J. van Houtum. Effect of carbon emission regulations on transport mode selection in supply chains. Working paper. Eindhoven University of Technology.

Intergovernmental Panel on Climate Change. 2007. Climate Change 2007: Synthesis Report. 
İşlegen,O., S. Reichelstein. 2011. Carbon capture by fossil fuel power plants: an economic analysis. Management Science. 57. 21-39.

Jacobsen, M. 2011. Fuel economy, car class mix and safety. American Economic Review. 101(3). $105-9$.

Kellner, F., J. Igl. 2012. Estimating the effect of changing retailing structures on teh greenhouse gas performance of FMCG distribution networks. Logistics Research. 4. 87-89.

Keskin, N., E. Plambeck. 2011. Greenhouse gas emissions accounting: allocation emissions from processes to co-products. Stanford University working paper.

Lawler, E.L., J.K. Lenstra, A.H.G. Rinnooy Kan, D.B. Shmoys (eds.). 1985. The Traveling Salesman Problem: A Guided Tour of Combinatorial Optimization. John Wiley \& Sons Ltd. New York.

Mak, H.Y., Z.J. Shen. 2010. Integrated supply chain design models. Wiley Encyclopedia of Operations Research and Management Science. ed. James J. Cochran. John Wiley \& Sons Inc.

Mak, H.Y., Z.J. Shen. 2012. Agility and proximity considerations in supply chain design - an analytical approach. Working paper. Hong Kong University of Science and Technology.

McKinnon, A., A. Woodburn. 1994. The consolidation of retail deliveries: its effects on CO2 emissions. Transport Policy. 1. 125-136.

Meier, F. 2012. Average age of U.S. cars up again in 2011, may now head down. USAToday.com. January 17.

Owen, D. 2009. Green Metropolis: Why Living Smaller, Living Closer, and Driving Less are the Keys to Sustainability. Penguin Group. New York.

Porteus, E. 2002. Foundation of Stochastic Inventory Theory. Stanford University Press. Stanford, California.

Papadimitriou, P. 1981. Worst-case and probabilistic analysis of a geometric location problem. Siam Journal of Computing. 10. 542-557.

Pancras, J., S. Sriram, V. Kumar. 2012. Empirical investigation of retail expansion and cannibalization in a dynamic environment. Management Science. forthcoming.

Shelling, T. 1992. Some economics of global warming. The American Economic Review. 82. 1-14.

Shen, Z.J., L. Qi. 2007. Incorporating inventory and routing costs in strategic location models. European J. of Oper. Res. 179. 372-389.

Shen, Z.J., C. Coullard, M.S. Daskin. 2003. A joint location-inventory model. Trasportation Sci- 
ence. 37. 40-55

Shoup, D. 2011. The High Cost of Free Parking. American Planning Association. Chicago, IL.

Shu, J., C.P. Teo, Z.J. Shen. 2005. Stochastic transportation-inventory network design problem. Operations Research. 53(1). 48-60.

Snyder, L., Z.J. Shen. 2011. Fundamentals of Supply Chain Theory. John Wiley \& Sons. Hoboken.

Stern, Sir N. 2007. The Economics of Climate Change. Cambridge University Press. Cambridge. United Kingdom.

Tol, R. 2008. The social cost of carbon: trends, outliers and catastrophes. Economics. (2).

Varian, H. 1984. Microeconomic Analysis. 2ed. W.W. Norton \& Company. New York.

Vlasic, B. 2011. Obama reveals details of gas mileage rules. New York Times. July 29.

Whitaker, R. 2012. Personal communication with Executive Vice President of Store Operations, Victoria Secrets.

Weitzman, M.L. 2007. A review of The Stern Review on the Economics of Climate Change. J. of Economic Review. 45. 703-724. 